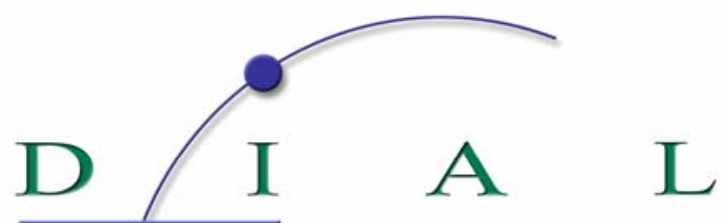

Développement Institutions \& Analyses de Long terme

DOCUMENT DE TRAVAIL

DT/2007-07

\title{
Focused Targeting against Poverty Evidence from Tunisia
}

Christophe MULLER

Sami BIBI

DIAL・4, rue d’Enghien • 75010 Paris•Téléphone (33) 0153241450 • Fax (33) 0153241451 E-mail : dial@dial.prd.fr • Site : www.dial.prd.fr

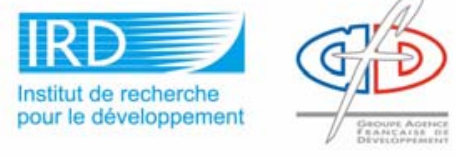




\section{Contents}

1. INTRODUCTION

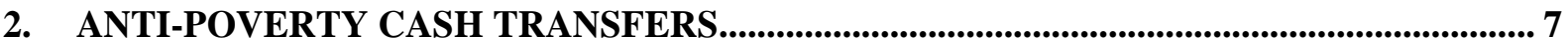

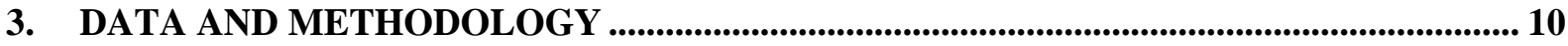

3.1. The data ................................................................................................................................................... 10

3.2. Results for living standard prediction ........................................................................................... 10

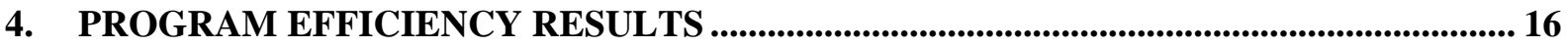

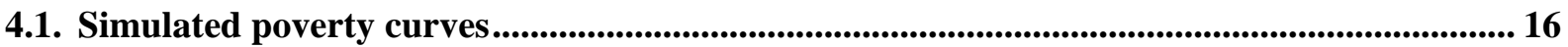

4.2. Measures of targeting efficiency....................................................................................................... 19

4.3. Policy consequences .............................................................................................................................. 24

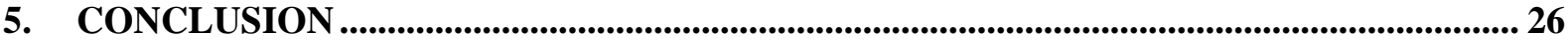

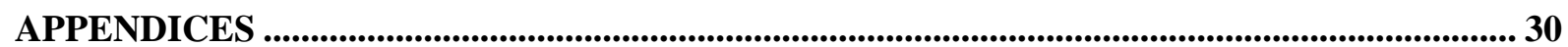

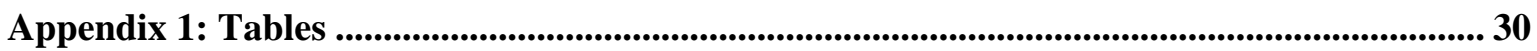

Appendix 2: The estimation of the equivalent-incomes ................................................................ 39

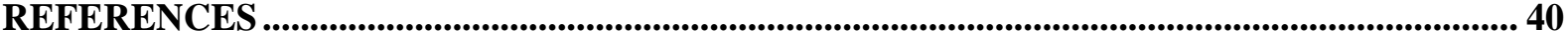

\section{List of tables}

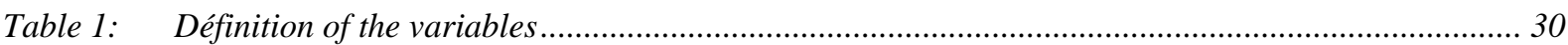

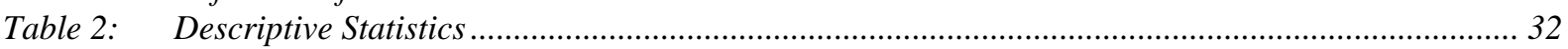

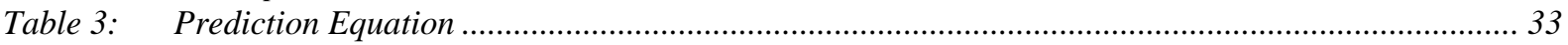

Table 4: $\quad$ Variance of the Prediction Errors over the Variance of the Logarithms of Living Standards........... 36

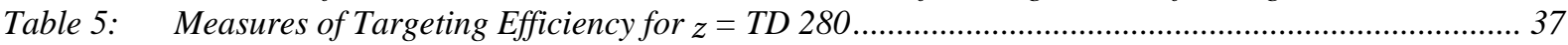

\section{List of figures}

Figure 1: Differences of Poverty Curves (1)

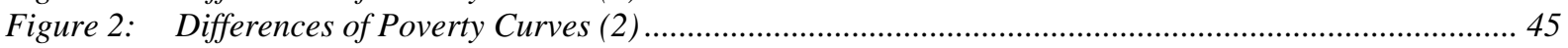




\title{
Focused Targeting against Poverty Evidence from Tunisia
}

\author{
Christophe Muller ${ }^{1}$ and Sami Bibi ${ }^{2}$
}

\author{
December 2006
}

\begin{abstract}
This paper introduces a new methodology to target direct transfers against poverty. Our method is based on estimation methods that focus on the poor. Using data from Tunisia, we estimate 'focused' transfer schemes that highly improve anti-poverty targeting performances. Post-transfer poverty can be substantially reduced with the new estimation method. In terms of $\mathrm{P}_{2}$, the most popular axiomatically valid poverty indicator, moving from 1.30 , the level reached under subsidies, to 0.36 , the level reached with the best OLS method, costs about 2.9 percent of GDP. An additional reduction down to 0.25 , that is another 30 percent reduction in poverty, requires only a few hours of statistician work. Finally, the obtained levels of under-coverage of the poor is so low that 'proxy-means' focused transfer schemes becomes a realistic alternative to price subsidies, likely to avoid social unrest.
\end{abstract}

Key Words: Poverty; Targeting; Transfers. JEL classification: D12; D63; H53; I32; I38.

We are grateful to the INS (National Institute of Statistics of Tunisia) that provided us with the data. This paper has been supported by the ESRC under the grant no. R000230326. This allowed the employment of the second author as a research assistant. The first author is also grateful for the financial support by Spanish Ministry of Sciences and Technology. Project No. SEJ2005-02829/ECON and by the Instituto Valenciano de Investigaciones Economicas. Usual disclaimers apply. We thank G. Kingdon, J.-Y. Duclos and participants in conferences and seminars in the Universities of Oxford, Alicante, Nottingham, Sussex, GREQAM-Aix-Marseille II in Marseille, Yonsei University in Seoul, at the ECINEQ conference in Palma de Majorca and at the NEUDC conference in Cornell for their comment.

\section{Introduction}

Transfer schemes are one of the main policy tools to alleviate poverty. Cash transfers are the proviso of assistance in cash to the poor or to those who face a risk of falling into poverty.

\footnotetext{
${ }^{2}$ Corresponding author. Departamento de Fundamentos del Análisis Económico, Campus de San Vicente, Universidad de Alicante, 03080 Alicante, Spain. E-mail: cmuller@merlin.fae.ua.es.

${ }^{2}$ Faculté des Sciences Economiques et de Gestion de Tunis (FSEGT) et Unité de Recherche en Econométrie Appliquée (URECA), Campus Universitaire, Bd. 7 Nov. El Manar 2092 Tunis, Tunisia. E-mail: samibibi@gnet.tn.
} 
The schemes (also called 'proxy means tests') are based on predictions of household living standards used to calculate the transfers. Such predictions are obtained by using household living standard survey data for regressing the living standard variable on household characteristics easy to observe.

Many countries have been using proxy means testing to target transfers, particularly in Latin America and the Caribbean, such as Chile for many years under the Ficha CAS system, Columbia under SISBEN, Mexico under the Oportunidades Program, Nicaragua, Jamaica, etc. In these countries, many theoretical and practical issues related to proxy means testing have been studied. The performance of the estimated transfer schemes is very variable (Coady et al., 2004). Raising their impact on poverty is of paramount importance as stressed in de Janvry and Sadoulet (2006b). However, the statistical foundations of these programs have not received the attention that it deserves. We fill this gap in this paper.

In this paper, we propose an estimation method of anti-poverty transfer schemes that focus on the poor and the near poor, thereby dramatically improving the scheme performance. We apply our new method to Tunisia. Our aim is to improve anti-poverty schemes and our methodological procedure is a part of the answer on which we concentrate in this paper.

In Tunisia, targeting transfers to poor people has become increasingly urgent because structural adjustment programs have imposed cuts in food subsidies, traditionally the main way to fight poverty. This is all the more so that the leakage from food subsidies to non-poor people is considerable, while failure to substantially serve all in the target group is common. The Tunisian Universal Food Subsidies Programme (TUFSP) is the main policy for alleviating poverty in Tunisia. Since 1970, basic foodstuffs have been under subsidy to protect the purchasing power and the nutritional status of the poor. Even if beneficial to the poor, this program was inefficient and costly. Indeed, about 2.9 percent of GDP was spent in subsidies by 1990 (10 percent of total government expenditure, and still slightly less than two percent 
nowadays). Furthermore, the richer households received much more from the program than the poor. Improvement of this subsidy program has been found limited by preference patterns, income inequality and the size of individual subsidies (Alderman and Lindert, 1998). In such situation, transfer schemes might alleviate poverty at a lower budgetary cost, provided that the method used to design the scheme performs well, as argued by Alderman and Lindert. This is consistent with one of the three key challenges identified by the World Bank to meet the goals of the $10^{\text {th }}$ Economic Development Plan: to strengthen the performance of social programs while maintaining budget balances (The World Bank, 2004). Meanwhile, maintaining social stability through a better safety net is still a major challenge in Tunisia (Hassan, 2006). However, a past substitution of food subsidies with direct cash transfers to the poor ended in riots in the 1980s because the proposed transfer system was perceived as leaving aside a large proportion of the poor. Other issues about social welfare, inequality and horizontal inequity could be raised about such policies in Tunisia (as in Bibi and Duclos, 2006). In this paper we focus on poverty.

Although living standards are measured with household surveys, they are generally badly known for the households that are not surveyed. Many authors have studied or discussed assistance to poor people based on targeting when some characteristics of individuals can be observed, but not income. ${ }^{3}$ Recently, Coady et al. (2004) review 122 targeted antipoverty programs in 48 countries. Cash transfers based on proxy means tests are generally found to provide the best results, although there is an enormous variation in targeting performances. They also find that targeting performance is better in rich countries and where governments are accountable. Lindert et al. (2005) measure the redistributive

\footnotetext{
${ }^{3}$ For instance, see Ravallion (1991), Besley and Coate (1992), Glewwe (1992), Besley and Kanbur (1993), Datt and Ravallion (1994), Slesnick (1996), Chakravarty and Mukherjee (1998), Ahmed and Bouis (2002), Coady et al. (2002), Schady (2002), Tabor (2002a,b), Coady et al. (2004), Lindert et al. (2005), Africa Focus (2006), DFID (2006), Gassman and Notten (2006).
} 
power of 56 transfer programs in 8 countries. They find that public transfers can be an efficient way of redistributing income, but often fail to do so. Moreover, the coverage of the poor is found far from 100 percent for the studied cash transfer programs. Some transfer programs are conditional on pre-specified behavior by beneficiaries (e.g., child school attendance or child vaccination). We do not deal with these programs in this paper. The interested reader can consult de Janvry et al. (2006) and de Janvry and Sadoulet (2006a,b) for comparisons of conditional and unconditional cash transfers.

In Latin America and Caribbean countries at least, there is little evidence of labor disincentives from public transfers. Ravallion (2005) argues that the tradeoffs equity/efficiency and insurance/efficiency restraining the scope for attacking poverty using transfers have been much exaggerated, and may not even be binding because of market failures. So, concentrating on simple optimization programs omitting these trade-offs and incentive problems makes sense.

Ravallion and Chao (1989) model the targeting problem as one of minimizing some specific poverty measures subject to a given anti-poverty budget by using geographical groups of individuals. Additional correlates of household living standards can also be used (Glewwe, 1992).

In practice, anti-poverty targeting can be based on predictions of household living standards, generally obtained from ordinary least squares (OLS) regressions on observed characteristics. However, the OLS method is anchored on the mean of the dependent variable (e.g., household living standard) and should provide accurate predictions around this mean mostly, which is often far from the poverty line. Then, the predicted living standards of the poor and near poor may be inaccurate. This explains why significant undercoverage of the poor is common (as in Grosh and Baker, 1995). This is the case when the mechanisms explaining the living standards of the non-poor differ from those of the poor. The latter is 
expected because poor households differ from other households not only by their capital and skills, but also by their access to social networks and credit possibilities, and by their economic activities.

In this situation, using OLS predictions may be sub-optimal. In this paper, we use estimation methods that 'focus' on the poor, so as to improve the predictions of the living standards for the poor and near poor households. The method we propose can be adapted to any social program that allows for 'household assessment', that is for predictions of household characteristics of (as in Case and Deaton, 1996, or Hanmer et al, 1998). Thus, health policies directed to ill persons, education policies directed towards underperforming students, pensions to the elderly, and any policy associated to specific intervals of the distribution of a social variable imperfectly observed could benefit from using our focused targeting approach.

Various estimation methods are possible for this purpose. For example, a semi-nonparametric estimation of the income distribution could be implemented by using kernel estimation methods in which correlates are parametrically incorporated (e.g., Pudney, 1999). Even full non-parametric estimation of conditional distributions of living standards could seem adapted to the problem at hand. However, nonparametric methods suffer from slow consistency, are little accurate for estimating the distribution tail, and are subject to the 'multidimensional curse' requiring unavailable large information because of many correlates included in proxy means tests. Moreover, analysts operating in statistical institutes in LDCs favor simpler estimation methods. Accordingly, Deaton (1997) insists on methods that can be actually implemented in the relevant institutions.

For these reasons we adopt two simple restrictions of the predictive regressions: (i) censoring the dependent variable to eliminate the influence of observations located far from the poverty line; (ii) using quantile regressions. The knowledge of the quantile regressions 
centered on all observed quantiles is equivalent to the knowledge of the empirical conditional distribution. Of course, there are too many quantiles to consider for a practical procedure, while good results may be obtained by just trying one quantile close around the poverty line. Then, focusing on the poor means that the predictions are calculated by defining the quantile regression or the censorship in terms of living standard levels judged representative of the poor or the near poor.

Another important issue is that OLS estimates for anti-poverty schemes are sensitive to the presence of outliers, to the non-normality of error terms with finite sample size, to heteroscedasticity and other misspecifications. Quantile regressions deal with these concerns for robustness (Koenker and Bassett, 1978), crucial in poverty analysis because of measurement errors in consumption surveys and the non-robustness of many poverty measures (Cowell and Victoria-Feser, 1996). Censored quantile regressions have been found useful to obtain robust explanations of chronic and seasonal-transient poverty (Muller, 2002).

What we predict is a chosen quantile of the distribution of the living standards conditionally on the correlates. This method has two shortcomings. Firstly, if the error terms are approximately normal, some efficiency may be lost as compared with OLS. Secondly, the focus is conditional on the set of correlates. That is, the chosen quantile is not that of the dependent variable, but the quantile of the error term in the estimated equation. However, that is precisely the quantile of the error that may matter most if one is interested in the prediction error that affects the transfer scheme performance.

As mentioned above, a better focus of the scheme can also be obtained by eliminating part of the income distribution (the richest households for example) from the prediction. This suggests using Tobit regressions and censored quantile regressions instead of respectively OLS and quantile regressions. 
Another interest of focused targeting is that it is logically related to the theoretically optimal transfer schemes with the transfers concentrated towards the poorest of the poor, the richest of the poor, or both (Bourguignon and Fields, 1997). From this theoretical perspective what need to be determined are the transfers to these sub-populations. Then, focused predictions of the living standards of the poor and near poor may generate more efficient transfers.

Is it possible to improve anti-poverty targeting by using living standard predictors that focus on the poor or near poor? The aim of the paper is to explore this question. However, our intention is not to propose a detailed reform of the anti-poverty policy in Tunisia, nor to deal with all the practical implementation difficulties of such policy. Section 2 presents the antipoverty transfer schemes. In Section 3, we apply our new method to the 1990 Tunisian household survey. In Section 4, we discuss program efficiency results. We find that: (1) focused targeting would reduce poverty much more than targeting based on OLS, and (2) undercoverage of the poor can be massively reduced. Finally, Section 5 concludes this paper.

\section{Anti-Poverty Cash Transfers}

This paper is based on the following popular poverty measures of the FGT class (Foster et al., 1984) because of their attractive axiomatic properties: $P_{\alpha}(z, Y)=\int_{0}^{z}\left(\frac{z-y}{z}\right)^{\alpha} f(y) d y$, where $z$ is a pre-specified poverty line, $f($.$) is the c.d.f. of household income y$ (or household living standard) and $\alpha$ is a poverty aversion parameter. ${ }^{4}$ Naturally, our approach could be

\footnotetext{
${ }^{4}$ The $\mathrm{P}_{\alpha}($.$) is the head-count ratio if \alpha=0$, the poverty gap index if $\alpha=1$, and the poverty severity index if $\alpha=$ 2. The FGT poverty measures satisfy the transfer axiom if and only if $\alpha>1$, and the transfer sensitivity axiom if and only if $\alpha>2$. All these measures satisfy the focus axiom and are decomposable.
} 
extended to other poverty measures. Given an anti-poverty budget, one must design transfers that optimally allocate this budget across households.

Let us first consider the situation when $Y$ (the vector of incomes in a population before applying the vector of transfers $T=\left\{t^{i}, i=1, \ldots, N\right\}$ is perfectly observed. In that case, the optimal transfer allocation is the solution to:

$$
\begin{aligned}
& \operatorname{Min}_{\left\{\mathrm{t}^{i}\right\}} \mathrm{P}_{\alpha}(z, Y+T) \equiv \frac{1}{N} \sum_{i=1}^{N}\left(\frac{z-\left(y^{i}+t^{i}\right)}{z}\right)^{\alpha} I_{\left[y^{i}+t^{i}<z\right]} \\
& \text { subject to } \\
& \sum_{i=1}^{N} t^{i}=B, \quad \text { with } t^{i} \geq 0, \forall i,
\end{aligned}
$$

where $N$ is the population size, $B$ is the budget to allocate, $t^{i}$ is the non-negative cash transfer to household $i$ and $y^{i}$ is pre-transfer income. The objective function can be weighed by the household size (or some equivalent-scale) in each household to deal with poverty at the individual level rather than the household level. However, for expositional simplicity, we neglect for the moment the possibility that households may include several members. We do not consider how the budget $B$ is funded. When $Y$ is perfectly observable, the solution to this problem is referred to as 'perfect targeting' and denoted $t^{i}$ for household $i$.

Bourguignon and Fields $(1990,1997)$ show that perfect targeting minimizing the headcount ratio would start awarding transfers so as to lift the richest of the poor out of poverty: $t^{i}=z-y^{i}$ if $y^{i}<z, t^{i}=0$ otherwise (in a decreasing order of income until all the budget is exhausted, 'r-type transfer'). In contrast, if the aim is to minimize a FGT poverty measure satisfying the transfer axiom $(\alpha>1)$, it is optimal to start allocating the anti-poverty budget to the poorest of the poor ('p-type transfer'). In that case, the transfer scheme would be: $t^{i}=y_{\max }-y^{i}$ if $y^{i}<y_{\max } ; t^{i}=0$ otherwise, where $y_{\max }$ is the highest cut-off income allowed 
by the budget. As the anti-poverty budget rises, $y_{\max }$ increases up to the poverty line, $z$, and perfect targeting would permit to lift all the poor out of poverty.

Unfortunately, perfect targeting is not feasible because incomes cannot be perfectly observed. Nevertheless, since the household living standards are correlated with some observable characteristics, it is possible, as in Glewwe (1992), to minimize an expected poverty measure subject to the available budget for transfers and conditioning on these characteristics. In practice, the approach followed in the literature or by practitioners for designing the transfer scheme is to replace unobserved living standards by predictions based on observed variables.

Let us first recall the standard procedure used in the literature for such predictions. Several empirical articles on anti-poverty targeting have appeared in the literature ${ }^{5}$ They generally follow a two-step procedure. First, the expectation of $y^{i}$ conditional on $x^{i}$ (the vector of living standard correlates for household $i$ ) is parametrically estimated by OLS. Then, if the budget allows it, each predicted poor household receives the difference between its predicted income and the poverty line. Other dependent variables, or even composite measures of welfare such as principal components extracted from multivariate analysis could be used in such regressions, sometimes with a change in the meaning of the objective function. Our method can be easily adapted to these cases.

Some authors have assumed that there is no question with this model to assume that $x^{i}$ causes $y^{i}$, but only that $x^{i}$ can be used to predict $y^{i}$. However, endogenous variables would lead to inconsistent parameter estimates and therefore inconsistent predictions of $y^{i}$. Moreover, some variables could be easily modified by the households, raising moral hazard problems. We deal with this issue by avoiding as much as possible endogenous regressors, and by considering alternative sets of correlates, defined by their increasing presumed endogeneity.

\footnotetext{
${ }^{5}$ Glewwe and Kanaan (1989), Glewwe (1992), Grosh and Baker (1995), Ravallion and Datt (1995), Bigman and Srinivasan (2002), Park et al. (2002), Schady (2002), Tabor (2002a,b).
} 
What matters for anti-poverty targeting is the ability to identify the poor and predict their living standards. Our strategy is to focus on the poor and the near poor when predicting living standards. Grosh and Baker (1995) improve targeting accuracy when using only the poorest 50 percent of the population. However, we prefer to use censorship that is likely to provide better results than truncation since it does not throw away valuable information about the identification of the poor and of the non-poor.

In this situation, if the error term in the latent equation of this model is normal, living standard predictions can be obtained by using a Tobit model, conditional upon some household characteristics. However, several issues may cause Tobit estimates to be inconsistent. First, the normality assumption on which the Tobit model is based is often rejected even for logarithm of living standards. Second, heteroscedasticity is likely to arise from household heterogeneity. Finally, the threshold $y_{\max }$ may be unknown. We deal with these difficulties by also using censored quantile regressions that are little sensitive to them ${ }^{6}$.

We now turn to the estimation results. We start by presenting the data used for the estimations.

\section{Data and Methodology}

\subsection{The data}

We use data from the 1990 Tunisian consumption survey conducted by the INS (National Statistical Institute of Tunisia). Unfortunately, this is the most recent complete national consumption survey data available in Tunisia, where official data dissemination rules are stringent. The survey provides information on expenditures and quantities for food and

\footnotetext{
${ }^{6}$ Other attempts to improve the focus on the poor could be based on combining census data and household survey data, although Bigman and Srinivasan (2002) and Schady (2002) found that the improvement in targeting in India and Peru are small. More recently, Elbers, Lanjouw and Lanjouw (2003) provide encouraging results for poverty estimation. We do not deal with this approach in this paper, which may not be well adapted to targeting schemes since census are conducted in special years, while transfer schemes may necessitate fresh information on household characteristics each year.
} 
non-food items for 7734 households. Usual other information from household surveys is available such as the consumption of own production, education, housing, region of residence, demographic information, and economic activities.

Because the estimation of equivalence scales based on cross-section data has often been criticized, ${ }^{7}$ and in order to concentrate on the issue of imperfect targeting, we assume that per capita consumption expenditure is an adequate indicator of each household member's welfare.

We define in Table 1 the correlates of living standards used for the predictions. The correlates are grouped according to increasing difficulties of observation by the administration and increasing ease of modification or hiding by households. Set I contains regional dummies. Using it along with OLS corresponds to 'regional targeting' and the regional poverty profile estimated in Muller $(2000)^{8}$. Set II includes regional and demographic information on households and characteristics of the household's dwelling. Set III adds information on the occupation and the education of the household's head to that in Set II. The variables in Set II are unlikely to be manipulated by households and could be cheaply observed, yet those added in Set III are easier to conceal.

It has been found that price differences across households may affect poverty measurement (Muller, 2002). In order to correct for this, account for substitution effects caused by price subsidies and control for spatial price dispersion, we estimate the equivalentgain from food subsidies, $\Gamma$. The calculus of $\Gamma$ is explained in Appendix 2 and is derived from the estimation of a quadratic almost ideal demand system (QAIDS), described in Muller and Bibi (2006) and based on a modified Blundell-Robin estimator. Both income and poverty line are converted into equivalent income. As Deaton (1981) signals, nothing can be learned about commodity taxes from consumer studies in which commodity demand functions assume

\footnotetext{
${ }^{7}$ Pollak and Wales (1979), Blundell and Lewbel (1991).

${ }^{8}$ For more information about regional targeting, see Kanbur (1987), Ravallion (1992), Datt and Ravallion (1993), Baker and Grosh (1994), Besley and Kanbur (1988), and Bigman and Fofack (2000).
} 
linear Engel curves. This and the obtained gain in accuracy in describing substitution effects justify basing the true price indices on the QAIDS. Our reference price system is the one without subsidies, which has the advantage of simplicity and puts all the considered policies on the same stand.

Then, they are four stages of estimation: (1) the estimation of a demand system to infer equivalent-incomes that enter the definition of living standard variable; (2) the prediction of living standards from observed characteristics; (3) the calculus of the optimal transfers corresponding to the predicted living standards, using perfect targeting optimization; (4) the simulation of the welfare effects of the transfer scheme. Let us turn to the living standard predictions.

\subsection{Results for living standard predictions}

Table 2 shows the descriptive statistics of the main variables used in the estimation. Mean total expenditure per capita is TD 804 (Tunisian Dinars). Tables 3 presents the results of OLS regressions, Tobit regressions (censored at 10\%), quantile regressions (anchored on the first decile) and censored quantile regressions (censored at 50\% and based on the first decile) of the logarithm of the household consumption per capita, on Sets I, II and III of explanatory variables ${ }^{9}$. Other conventions, for censorships and quantiles lead to results in agreement ${ }^{10}$. We use for the dependent variable the logarithm of the equivalent income (i.e. with living standards corrected with true price indices inferred from the estimated demand

\footnotetext{
${ }^{9}$ Other estimation methods could be used such as Probit models of the probability of being poor, or non-linear specifications for the right-hand-side variables. We tried a variety of such methods. However, to limit the length of the paper, we only show some of the better performing and more relevant estimates.

10 The censorship at quantile 50 percent of the censored quantile regression is chosen because of two requirements. First, censored quantile regression estimates are inconsistent if too few observations are present in the uncensored subsample (a condition is needed which is unlikely with a too small sample). Second, excessive censoring leads to disastrous loss of accuracy in the estimation.
} 
system $)^{11}$. Alternative results of this paper without adjustment or corrected by Laspeyres price indices are in agreement.

The censored quantile regression estimator for dependent variable $y_{i}$ and quantile $\theta$ is obtained as the solution to the minimisation of $1 / \mathrm{N} \sum_{\mathrm{i}} \rho_{\theta}\left[\mathrm{y}_{\mathrm{i}}-\max \left(0, \mathrm{X}_{\mathrm{i}}^{\prime} \gamma\right)\right]$, where $\rho_{\theta}[\mathrm{u}]=\{\theta$ $\left.-\mathrm{I}_{[\mathrm{u}<0]}\right\}|\mathrm{u}|, \mathrm{X}_{\mathrm{i}}$ is a matrix of regressors, $\gamma$ is a vector of parameters, $\mathrm{N}$ is the sample size. Quantile regressions correspond to replacing $\max \left(0, X_{i}^{\prime} \gamma\right)$ with $X_{i}^{\prime} \gamma$. Powell (1986) and Buchinsky and Hahn (1998) analyse these estimators. The estimation is obtained by a combination of a linear programming algorithm and sub-sample selection at each iteration of the optimisation. We estimate the confidence intervals of the censored quantile regression estimates by using the bootstrap method proposed by Hahn (1995) with 1000 bootstrap iterations.

It has been argued that quantile regressions could help poverty analysts by choosing quantiles corresponding to the poor (Buchinsky, 1994). The argument is overstated since the quantile is that of the conditional distribution, i.e. of the error term, and not of the living standard. However, for predicting the living standards of the poor or near poor, since the prediction errors mostly stem from the error terms in the living standard equations, quantile regressions anchored on small quantiles should improve the predictions for these subpopulations. Then, our choice of the quantile in the quantile regressions is motivated by the focus. This approach corresponds to specifying quantiles close to the poverty line in the living standard regressions.

Let us take a look in Table 4 at the ratios of the variance of the prediction errors over the variance of the logarithm of the living standards ${ }^{12}$. These ratios are measures of the prediction performance of the estimation methods for the mean of the logarithms of living

\footnotetext{
${ }^{11}$ To remain close to common practices we did not weigh the estimation by the sampling scheme. However, we checked that using sampling weights in this case yields similar results, in part because the sampling probability at each sampling stage of this survey are almost proportional to population sizes.

${ }^{12}$ The interpretation of the $\mathrm{R}^{2}$ as a percentage of variation explained is dependent on the use of OLS to compute the fitted values. This is why we use instead the ratio of variances as our prediction performance indicator.
} 
standards. They are provided for three subpopulations: the whole population of households, the households in the first quintile of the living standards, the households in the first and second quintiles. For the OLS, the considered ratio is equal to $1-\mathrm{R}^{2}$.

The results show that quantiles regressions (anchored at quantile 0.1) generally perform much better than the other methods for predicting the logarithms of living standards of the poor (here defined as belonging to the first or second decile of the living standard distribution), to the exception of censored quantile regressions that are better for the poor under the first quintile. In contrast, the best method for predicting the mean of the logarithms of living standards in the whole population is the OLS method. Predicting the logarithms of living standards by using Tobit regressions (with censorship at 10 or 30 percent) does not improve on OLS predictions for the whole population in this data set. Moreover, Tobit predictions for the poor remain much inferior to the predictions obtained with quantile regressions, and censored quantile regressions. Finally, the predicting performance of the censored quantile regressions is disappointing for the whole population, and dominated for the poor in the second quintile by that of the quantile regressions. This is worrying since realistic poverty lines in Tunisia lie between the first and second quintile. An additional difficulty with censored quantile regressions is that they rely on estimation algorithms difficult to implement in most national statistical institutes of less developed countries.

Then, if our business is predicting the logarithms of living standards of the poor or near poor, the quantile regressions look like the most promising method. In contrast, censoring living standards with Tobit models does not provide improved predictions for the poor.

Our approach consists in exploiting the better predictions from quantile regressions for the living standards of the poor to improve the performance of anti-poverty transfers. Appropriate assessment will be obtained by estimating the scheme with different methods and 
examining the results. We now turn to the results of the prediction equations in Table 3 , which, as a by-product, provide us with estimates of living standard explanations in Tunisia. The signs of most coefficient estimates (significant at 5 percent level) correspond to the expected effects of variables and are consistent across all estimation methods.

The dummy variable for Tunis is the reference. The dummy variable for the eastern regions (Northeast, Sfax, Southeast) have generally less negative coefficients. Residents in the East are richer than most other households, while poorer than households living in Tunis. This corresponds to well-known features of the geographical dispersion of the poor in Tunisia (The World Bank, 2000).

The two estimated coefficients associated with the age of the head imply an inverse-U shape effect consistent with life cycle theories. The other variables describing household composition have almost always negative effects. Indeed, numerous members in young age classes generate high economic burden. In contrast, the variables describing the activities of members, the numbers of active members by gender and the number of adult members over 19 years old, have positive effects associated with members' contributions to household income. As expected, the male contribution is larger than the female one. The coefficients of the housing characteristics have signs consistent with durable consumption and investment decisions that are correlated with household income. Living in a flat and the number of rooms per capita are positively associated with living standards. Hovel or arab house dwellers are relatively poorer. Households who rent or those who acquired their lodgings on lease are generally better off. This is consistent with the higher cost of these accommodation options.

The estimated negative coefficients describing the school participation of children reflect corresponding expenditure. In contrast, the estimated positive coefficients of the education level of the household head are related to the returns to past human capital 
investment. Then, households with more children at school are on average poorer, while households with better educated heads are richer.

The omitted occupation categories are 'managers, executives and other qualified white collar or self-employed workers'. The household heads in these categories are generally not poor, which explains the negative coefficients of the included occupations. Households whose head are unemployed or are agricultural labourers are often less well off. However, agricultural labourers in the Southwest (respectively the Southeast), where rain is scarcer and aridity is fiercer (respectively less scarce, respectively less fierce), are more (respectively less) handicapped by their occupation than agricultural labourers in other regions. Households whose head is an industry worker have intermediate living standards between those of agricultural labourers and farmers.

In the next step in the analysis, the predicted household living standards are used to simulate poverty levels resulting from the targeting scheme, first by using poverty curves.

\section{Program Efficiency Results}

\subsection{Simulated poverty curves}

The calculation of the transfer $\mathrm{T}_{\alpha}($.$) in the simulations, according to the Bourguignon$ and Fields' rule, requires the determination of the cut-off income, $y_{\max }$, beyond which no transfer takes place. The r-type transfer is: $y_{\max }$ minus the predicted income, for each household predicted poor. Under perfect targeting, the $y_{\max }$ permitted by the budget currently devoted to food subsidies is TD 358 (Tunisian Dinars), greater than poverty lines estimated 
for Tunisia. ${ }^{13}$ Even if the budget is sufficient to eliminate poverty under perfect targeting, under imperfect targeting additional resources are necessary, and the budget is exhausted. We present our simulation results in the form of poverty curves describing stochastic dominance situations.

In Sub-Section 4.2., we shall use a poverty line equal to TD 250 to estimate targeting efficiency measures, consistently with the most credible poverty line in The World Bank (1995), corresponding to a head-count index of 14.1 percent. This poverty line corresponds to an equivalent poverty line of TD 280 without subsidies. However, the qualitative results of this paper go through with poverty lines at reasonable levels, as is illustrated in the poverty curves.

The top of Figure 1 shows the upper ('max') and lower ('min') curves corresponding to the 5 percent bootstrap confidence bounds of $\Delta \mathrm{P}_{0}$ (difference in the head-count indices) respectively obtained with: (1) the transfer scheme based on one of the estimation methods and (2) the food subsidies. These curves exhibit the significance of the differences in the proportion of the poor obtained after the implementation of the two considered policies under fixed budget and for a range of poverty thresholds. That is: a transfer method significantly first-order dominates price subsidies if the lower bound curve of the interval is over zero. The results show that all the considered transfer methods (except Tobit for a short interval of poverty lines) significantly first-order dominate price subsidies for all reasonable levels of the poverty line. This is confirmed by Figure 1 that exhibits the same type of curves, while for the second order stochastic dominance (differences in Poverty Gaps, $\Delta \mathrm{P}_{1}$ ). Clearly, all the considered situations correspond to lower poverty levels reached by the transfer schemes as

\footnotetext{
${ }^{13}$ The poverty line estimated by the National Statistic Institute and the World Bank (1995) - see also Ravallion and van der Walle (1993) - on the basis of needs in food energy corresponds to TD 196, the poverty lines by Ayadi and Matoussi (1999) vary between TD 213 and 262, and the poverty lines by Bibi (2003) vary between TD 227 and 295. Poverty lines calculated by the World Bank for 1995 (The World Bank, 2000) are between TD 252 to TD 344 .
} 
compared to the case of subsidies. Aggregate poverty would be diminished by implementing these transfer schemes in place of price subsidies.

Figure 2 shows the 5 percent bootstrap confidence intervals of the poverty curves obtained with two transfer schemes based on two prediction methods among: OLS, Tobit, quantile regressions and censored quantile regressions anchored on the first decile and censored at 50 percent. Here, the first-order dominance (poverty measured by the head-count index) is insufficient to produce an unambiguous ordering of these methods. In contrast, for realistic poverty lines, with the second-order dominance (poverty measured by the poverty gap), the estimates of poverty after the transfers based on quantile regressions are significantly second-order dominated by poverty after Tobit-based transfers, which is itself second-order dominated by poverty after OLS-based transfers. These results are valid for any poverty line below a threshold well above TD 280 , the poverty line we use in the next section to assess the targeting efficiency. In contrast, for unrealistically high poverty lines, the performance of quantile-regression-based transfers is clearly less good than that of OLS- and Tobit-based transfers. This illustrates the specificity of the 'focus' on low-incomes for quantile-regression-based transfers.

Thus, the resulting ranking of the curves in terms of poverty reduction across the considered estimation methods is akin to the ranking that has been found for the goodness-offit of the logarithm of living standard regressions for the poor. The ordinal comparison results across curves are robust to using alternative price indices to deflate the household living standard. Moreover, the curves show that the bulk of the gain obtained with our new method corresponds to a population of the poor whose living standards are much below the half-mean of the living standard distribution.

The better performance of quantile regressions may be attributed to the focus properties of this method. However, an alternative interpretation could be that the robustness 
of the quantile regressions is what matters in practice. To control for this we run Huber robust regressions. Huber regressions yield almost the same results than OLS whether for the estimated coefficients or for the poverty curves. The better performance of the quantile regressions for anti-poverty targeting schemes is therefore not due to robustness. However, poverty curves provide only qualitative insights. We now turn to quantitative estimatees of targeting efficiency.

\subsection{Measures of targeting efficiency}

We first devote a few words to a few measures of targeting efficiency of the transfer scheme. With imperfect targeting, only poor people who are predicted as poor can benefit from poverty alleviation (i.e. provided their predicted living standard is below the threshold $y_{\max }$ for a 'p-type' transfer, or between $y_{\max }$ and $\mathrm{z}$ for a 'r-type' transfer). On the other hand, non-poor people predicted as non-poor or with their predicted living standard in the above intervals bounded by $y_{\max }$, receive transfers. Thus, two types of errors characterize imperfect targeting. The Type I error (undercoverage), central in Ravallion (1991), is that of failing to reach some members of the targeted group. As Atkinson (1995) noted, this failure generates horizontal inefficiency when compared with perfect targeting. The Type II error arises where benefits are awarded to ineligible people under perfect targeting. The leakage of program benefits is obtained by adding (1) the transfers given to those whose pre-transfer income is above the poverty line, and (2) the transfers received by pre-transfer poor that are unnecessary because the post-transfer living standards are raised above the poverty line. ${ }^{14}$ The leakage ratio is obtained by dividing the leakage with the available budget. A final measure of the

\footnotetext{
${ }^{14}$ Grosh and Baker (1995) and Cornia and Stewart (1995) do not consider the second component of the leakage cost. Creedy (1996) distinguishes between vertical expenditure inefficiency, equal to the leakage ratio as estimated by Grosh and Baker (1995) and by Cornia and Stewart (1995), and poverty reduction efficiency equal to our leakage ratio.
} 
program efficiency is the reduction in poverty measures due to the transfer scheme: $\Delta \mathrm{P}_{\alpha}=\mathrm{P}_{\alpha}(z, Y)-\mathrm{P}_{\alpha}(z, Y+\hat{T})$, where $\hat{T}$ is the vector of the estimated transfer for each household $h .{ }^{15}$

To assess the performance of anti-poverty transfers, we compare the outcomes of the transfer scheme with those of the Tunisian food subsidy scheme, the main Tunisian poverty alleviation program. We compute the equivalent gain of the food subsidies scheme: $Y_{e}\left(p^{r}, p^{s}, Y\right)=Y+\Gamma$, where $Y_{e}($.$) is the equivalent-income function vector for observed$ households, $p^{r}$ is the reference price vector composed of the prices obtained without food subsidies, $p^{s}$ is the price vector under food subsidies, and $\Gamma$ is the vector of the estimated equivalent-gains under food subsidies.

The poverty measure under price subsidies is calculated by transforming the incomes into their equivalent values when prices are the observed price vector $p^{s}$ instead of the reference price vector $p^{r}$. Since the poverty line $z=T D 280$ has been defined for the price vector without subsidies $p^{r}$, we have $Y_{e}\left(p^{r}, p^{r}, z\right)=z$. Then, $\mathrm{P}_{\alpha}\left[Y_{e}\left(p^{r}, p^{r}, z\right), Y_{e}\left(p^{r}, p^{s}, Y\right)\right]=$ $\mathrm{P}_{\alpha}(z, Y+\Gamma)$. The net effect on poverty of implementing direct transfers instead of price subsidies is: $\mathrm{P}_{\alpha}(z, Y+\hat{T})-\mathrm{P}_{\alpha}(z, Y+\Gamma)$.

Table 5 presents simulation results for: (1) two measures of targeting accuracy (leakage and undercoverage), and (2) the levels of poverty reached with the transfer schemes and with price subsidies. As mentioned above, a poverty line of TD 280 per capita per year without subsidies is used, consistently with The World Bank (1995). An individual having an income of TD 280 without subsidies has the same welfare level with TD 250 and subsided

\footnotetext{
${ }^{15}$ Other measures of transfer efficiency have been proposed, while we concentrate on the main indicators related to our concerns, in part to avoid drowning the reader under figures for a paper which already contains a lot of them. Bibi and Duclos (2006) propose indicators of horizontal inequity, Coady et al. (2004) and Lindert et al. (2005) propose to use the Distribution Characteristic Indicator, which shows the change in social welfare marginal benefit achieved by transferring a standardized budget to the program, and the Coady-Grosh-Hoddinott index, which allows the comparison of the actual performance to the outcome that would result from neutral targeting. Many inequality, concentration and progressivity indices could also be used.
} 
prices: $Y_{e}\left(p^{r}, p^{s}, 250\right)=Y_{e}\left(p^{r}, p^{r}, 280\right)$. We also find qualitatively similar conclusions for slightly lower poverty lines.

For all simulations and all the targeting criteria, the performance of the subsidies is much worse than that of any transfer scheme, except for undercoverage which is null with subsidies because all households consume at least one subsidized good. Then, we emphasize in our comments the comparison amongst transfer methods. The standard errors suggest that the estimated targeting indicators significantly vary with the prediction methods. This is indeed generally the case when tests of differences are implemented, as illustrated with the bootstrap intervals of Figures 1 and 2. The results based on regressor Set I, corresponding to regional targeting, show that this typical regional targeting scheme, based on OLS, improves on food subsidies in terms of the number of the poor remaining after the policy. However, if the aim is to reduce the number of the poor, the transfers based on quantile regressions anchored on the third decile are the best among the considered options. Meanwhile, if the aim is to reduce poverty measured by the poverty gap $\mathrm{P}_{1}$ or the poverty severity measure $\mathrm{P}_{2}$ quantile regressions anchored on the first decile are best. Moreover, leakage and undercoverage are also lower with this method.

However, the picture slightly changes when we extend the set of regressors. With regressor Set II, which adds information on dwelling and demographic characteristics to the information on regional dummies of Set I, substantial improvements can be reached whether in terms of poverty statistics, leakage or undercoverage. With Set II, the quantile regression based on the first quantile remains the best approach for reducing $\mathrm{P}_{2}$ and undercoverage. As it happens, these two criteria may often be considered decisive. Indeed, $\mathrm{P}_{2}$ gives a stronger weight to the poorest of the poor, which confers it better normative properties than $\mathrm{P}_{0}$ and $\mathrm{P}_{1}$. On the other hand, undercoverage is related to probably indispensable political conditions since policies leaving aside a large proportion of the poor are unlikely to be implementable in 
Tunisia. Censored quantile regressions allow us even larger reduction of undercoverage, although they are less straightforward to implement. However, with Set II if the aim is merely to diminish the number of the poor, OLS based transfers would provide better results, while if the aim is to reduce $\mathrm{P}_{1}$ or leakage, the quantile regressions based on the third decile would be preferable.

Introducing information on educational level or occupation of households' head produces little progress. The quantile regressions based on the first decile (and sometimes the censored quantile regressions) remain preferable if the aim is to alleviate $\mathrm{P}_{1}, \mathrm{P}_{2}$ and leakage, while OLS are better if the aim is to cut the number of the poor down. Using censored quantile regressions anchored on the first decile would lead to the lowest undercoverage. Meanwhile, quantile regressions based on the first decile, which are simpler to implement, still yield low undercoverage of about 8 percent. The other methods generally produce disastrous outcomes for undercoverage.

Omitting price correction or deflating with household Laspeyre price indices gives similar results. On the whole, the quantile regression based on the third decile most often appears as the best method for reducing $\mathrm{P}_{0}$, while the quantile regression based on the first decile is best for diminishing $\mathrm{P}_{1}, \mathrm{P}_{2}$, leakage and perhaps undercoverage. Often, the censored quantile regressions anchored on the first decile with a 50 percent censorship dominate the quantile regressions based on the first decile for reducing undercoverage, but they seem unlikely to be used in most applied contexts since this method is not available in standard statistical packages ${ }^{16}$.

Three important points may be noted. First, the gaps between the estimated reductions in $\mathrm{P}_{2}$ with different prediction methods are considerable. The statistical method used to design

\footnotetext{
${ }^{16}$ Note that a characteristic of the censored regression method is that it may coincide with quantile regression estimates for low quantile. This comes from the fact that both estimators are derived from solving linear programming problems that may yield the same optimal kink. Such situation occurred several times in our results.
} 
the transfer scheme is a crucial ingredient of the performance of the scheme. If we consider the results obtained with our best estimates (based on quantile regressions anchored on the first decile, especially for reducing $\mathrm{P}_{2}$, the progress is spectacular as compared to the results obtained with the subsidy scheme. An additional seven percent of the population potentially disappear from the poor with the new transfer method as compared with subsidies. Even when compared with other cash transfer methods, substantial improvement of the poverty situation measured by $\mathrm{P}_{2}$ can be obtained (from 0.36 with the best OLS method to 0.25 with the best quantile regression method). The percentage of excluded poor households from the scheme dramatically falls (to 8.1 percent) as compared with what is obtained with OLS predictions based on geographical dummies (for which it is 24.7 percent). Second, the usually employed method, based on OLS estimates, appears as the least performing approach compared to ways of focusing the predictions on the poor. However, when considering only the number of the poor, the OLS provide acceptable predictions for the richest of the poor that are not discounted when compared with the poorest. With limited budget, one could push still further the transfer performance by using quantile regressions centered about the poverty line for $\mathrm{r}$ type transfers and centered on small quantiles for p-type transfers, consistently with the theoretical definitions of these transfer types.

The censorship of the richer half of the sample is statistically too crude to make much impact on the performance of anti-poverty schemes through Tobit predictions even if they may slightly improve on OLS. Besides, Tobit regressions yield inconsistent estimates if the error terms in predicting equations are not strictly normal. Getting rid of the normality assumption by using censored quantile regressions generally yields worse results than what can be obtained with quantile regressions, except for undercoverage.

On the whole, using prediction methods focusing on the relevant part of the living standard distribution provides a way to substantially raise transfer efficiency. Quantile 
regressions are natural to carry out this task, as our results illustrates, since they can be centered on any chosen location of the conditional distribution of living standards. Even better results could be reached by trying a large set of quantiles instead of just using arbitrarily the first and second deciles to center the regressions. However, we did not want to 'force' the results by implementing these extensive tries, akin to data mining. For example it is likely that centering on quantile 0.14 , corresponding to the actual percentage of the poor, would be a good way of improve quantile predictions around the poverty line. Systematic search of the centering quantile, although time consuming, could be implemented in any context where a household living standard survey is available in order to optimize the transfer performance.

\subsection{Policy consequences}

What are the policy consequences of our new method of focused transfer schemes? Clearly, highly improved performances can be attained by adapting the statistical method used for the prediction of living standards. Lower poverty levels, smaller leakage and undercoverage statistics can be obtained by focusing the estimation of transfer schemes. In Tunisia, the gain of efficiency, notably in terms of undercoverage, is so large that it should deserve serious policy consideration. In terms of $\mathrm{P}_{2}$, the most popular axiomatically valid poverty indicator, moving from 1.30 , the level reached under subsidies, to 0.36 , the level reached with the best OLS method, costs about 2.9 percent of GDP. An additional reduction down to 0.25 , that is another 30 percent reduction in poverty, requires only a few hours of statistician work. Moreover, this reduction is much larger than that obtained by adding education and occupation variables to the list of regressors in OLS regressions.

The econometric results have shown that decisive progress can be reached in the design of the scheme. The choice of the econometric method for predicting living standards is crucial for the performance of the transfer scheme. Adopting an econometric method that 
focus on the poor improves the efficiency of the transfer scheme. In our data, the method of quantile regression centered on a quantile close to the expected poverty line provides the best results.

There is already a small transfer scheme in operations in Tunisia: the 'Programme des Familles Nécessiteuses' (République Tunisienne, 1991). However, to implement a large transfer program would necessitate raising large funds. A logical consequence of our analysis is to make possible the transfer of some of the public funds allocated to price subsidies towards a national focused transfer scheme. Our results show that in Tunisia an opportunity exists to reach much better objectives of poverty alleviation by substituting the in force price subsidies with direct transfers based on observable characteristics of households, and at a lower public cost.

This is all the more fortunate that price subsidies that distort prices are a source of inefficiency for the functioning of the whole economy. Thus, replacing price subsidies with direct transfers would not only alleviate poverty, but also improve market efficiency and thereby stimulate economic growth.

But growth is not everything. Previous attempts at eliminating subsidies in Tunisia ended in riots. Indeed, since all the poor, and other population categories, benefit from price subsidies, an economically better aid system to the poor based on direct cash transfers may alleviate poverty, but may also leave aside a large proportion of the poor. If this risk is perceived as high by the population, social unrest may follow, especially because the Tunisian society is very aware of social policies. Therefore, replacing subsidies by OLS-based transfers is likely to be impossible. Indeed, our results show that about between one quarter and one fifth of the poor would be excluded from the benefits of such transfers and would simultaneously lose the benefits they extract from subsidies. 
However, using focused transfers, would allow the government to reduce the undercoverage of the scheme to such a level (at most 6 percent of the poor in our estimates, which could still be improved), that: (1) the reform should be politically viable, and (2) the reform would not generate severe risks for a large proportion of the poor. As a matter of fact, it seems exceptional that such a limited proportion of the population would suffer from a large social reform. Moreover, considering the gain in efficiency caused by the elimination of price distortions, and the saving of public funds, the actual percentage of the poor suffering from the reform may even turn out to be negligible.

\section{Conclusion}

Leakage to the non-poor is often substantial from universal food price subsidy programs directed to the poor. Because of their large budgetary cost, many governments have moved away from them towards better targeted methods, such as proxy-means cash transfer. Indeed, benefits can be awarded to the poor contingently on their characteristics. However, transfer schemes may be inaccurate because the statistical predictions involved in their design are centered on the mean of the living standard distribution and not enough oriented towards the potentially poor.

This paper improves on past methods by focusing on the poor and near poor for the design of transfer schemes based on estimated living standard equations ${ }^{17}$. This is achieved by using quantile regressions and censorship for the prediction of living standards. This is not the object of the paper to delve into detailed practical analysis of the Tunisian anti-poverty policy nor to deal with all the implementation difficulties of this policy.

Our estimation results based on data from Tunisia reveal considerable potentialities for poverty alleviation with our new approach. The improvement is also substantial as compared

\footnotetext{
${ }^{17}$ Therefore, not for food subsidies for which distinguishing among households for eligibility of benefits is not feasible.
} 
to usual targeting schemes based on OLS predictions: with our method based on quantile regressions poverty could be massively reduced in Tunisia. Moreover, large reduction in undercoverage is possible, even when compared with the best OLS-based transfers. In contrast, censoring the living standard distribution does not improve the performance of transfer schemes, except for reducing undercoverage.

One shortcoming of transfer schemes is that some households may be able to change some of their characteristics by which they are targeted or to hide their true characteristics in an attempt to receive a larger transfer. Though, it is unlikely that the net benefit of such behavior will be non-negative for many characteristics, like location and dwelling types. In our results, the characteristics that can easily be modified or hidden by households (education and occupation variables) are precisely the ones that do not add much to the performance of the scheme.

Targeting by indicators may be relatively cheap to implement, as opposed to the huge financial burden of price subsidies. This is notably the case if it can be carried out just after a national census since the variables contributing to the efficacy of the transfer scheme are easy to observe from a census. Moreover, in such situation the scheme can be improved by using the methods in Elbers, Lanjouw and Lanjouw (2003), taking full advantage of the census information $^{18}$.

In the literature, most measured administrative costs of transfer schemes range from less than 5 percent to about 15 percent of the targeting budget (See Grosh and Baker, 1995, Coady et al., 2005, Alderman et al., 2005). Therefore, the conclusions of our study are unlikely to be offset by administrative costs only ${ }^{19}$. The fact that there already exists in

\footnotetext{
${ }^{18}$ It is likely that poverty mapping can be improved by estimating methods focusing on the poor. We leave this question for future work. Finally, the assessment of the welfare impact of public spending (van de Walle, 1998) could be based on focusing statistical approaches.

${ }^{19}$ Besley (1990) discusses the theoretical consequences of such costs and other costs of means testing. Other types of costs would come from the demeaning nature of transfers, as had been observed in the US with food stamps. However, monetary transfers, such as pensions are generally not considered demeaning, and the poor in Tunisia are generally needier than most of the poor in the US, and thus may not afford to be excessively proud.
} 
Tunisia small systems of direct transfers to: the elderly, the handicapped, schoolchildren, and needy families, suggest that administrative implementation on a larger scale is doable.

However, the implementation of direct cash transfer programs is likely to meet two difficulties. First, the program administration may be complex. In particular, updating the eligibility lists is costly and subject to political and social bias (as in Park et al., 2002). Moreover, overlap between different assistance programs may make their management delicate. All this could be dealt with by studies of the administrative implementation of these programs. Notably, relying on decentralized administrations may be more efficient, as was found in Bangla-Desh (Galasso and Ravallion, 2005), although more ambiguous results are found to West Bengal by Bardhan and Mookherjee (2006).

Moreover, changing the assistance system in Tunisia implies that some households will lose from such change. In such situation, the considerable leakage of the assistance system would imply that the potential losers in the change would be likely to oppose it. The social troubles in 1984, after the first attempt to eliminate food price subsidies, have encouraged caution in political circles against replacing these subsidies by direct transfers. Our new focused approach provides an opportunity to change the political balance of antipoverty policies in Tunisia (and in other countries such as Egypt where a similar situation exists, see Ahmed and Bouis, 2002, and Gutner, 2002) in that focused transfers only leave aside a very small proportion of the poor, and are likely to increase market efficiency, thus contributing to stimulate growth. What seems needed in this context is first a special effort of public explanation of the benefits of focused direct transfers against price subsidies, and second a system of compensation, e.g. by creating new jobs from the saved funds, aimed at the few households the most likely to suffer from the suppression of price subsidies.

Another related approach would be to mix subsidies and cash transfers. Such a program can be politically easier to implement. It would allow government to lower the 
perception of undercoverage since the poor who do not benefit from the transfer program could still be helped by some price subsidies.

Other econometric ways of focusing on the poor are possible, for example by using non-parametric regressions, shadowing the shape of the living standard distribution. It is unclear what the optimal econometric techniques to use to implement this focus concern are and we conjecture that they may depend on the data at hand. On the whole, the important point in our approach is the adaptation of the estimation method for household living standard predictions in order to improve the performance of the anti-poverty targeting scheme. Using quantile regression improves this performance dramatically in the case of Tunisia. However, other variants and improvement are probably possible and left for future work. 


\section{Appendix 1: Tables}

Table 1: Definition of the variables

\begin{tabular}{|c|c|}
\hline \multicolumn{2}{|l|}{ Set I: } \\
\hline Great Tunis & 1 if household lives in Great Tunis, 0 otherwise. \\
\hline Northeast & 1 if household lives in Region Northeast, 0 otherwise. \\
\hline Northwest & 1 if household lives in Region Northwest, 0 otherwise. \\
\hline Middle east & 1 if household lives in Region Middle east, 0 otherwise. \\
\hline Middle west & 1 if household lives in Region Middle west, 0 otherwise. \\
\hline Sfax & 1 if household lives in Sfax, 0 otherwise. \\
\hline Southeast & 1 if household lives in Region Southeast, 0 otherwise. \\
\hline Southwest & 1 if household lives in Region Southwest, 0 otherwise. \\
\hline Complement for Set II: & \\
\hline Demographic information & \\
\hline $\mathrm{Nc} 2$ & Number of children in household old less than 2 years old \\
\hline Nc3-6 & Number of children aged between 3 and 6 years. \\
\hline Nc7-11 & Number of children aged between 7 and 11 years. \\
\hline $\mathrm{Na} 12-18$ & Number of adults aged between 12 and 18 years. \\
\hline $\mathrm{Na} 19 \mathrm{p}$ & Number of adults old more than 19 years. \\
\hline Age & Age of the household head (HH). \\
\hline Age2 & Squared age of the HH. \\
\hline Type of house & \\
\hline Nbroompc & Number of rooms per capita \\
\hline Detached House & 1 if household lives in a detached house, 0 otherwise. \\
\hline Flat & 1 if household lives in a flat, 0 otherwise. \\
\hline Arab house & 1 if household lives in an Arab house, 0 otherwise. \\
\hline Hovel & 1 if household lives in a hovel, 0 otherwise. \\
\hline Accommodat & \\
\hline Owner & 1 if household is owner of the house. \\
\hline Rent & 1 if household is renting a house. \\
\hline Locvte & 1 if household has a leasing agreement for his house \\
\hline Free & 1 if household lives in a free of charge house. \\
\hline
\end{tabular}




\begin{tabular}{|l|l|}
\hline Complement for Set III: & \\
Occupation of HH & Dummy variable for HH is unemployed. \\
Unemp & Dummy variable for HH living in the Southeast and agricultural labourer. \\
Agrilab-sw & Dummy variable for if HH living in the Southwest and agricultural labourer. \\
Agrilab-an & Dummy variable for if HH living in another region and agricultural labourer. \\
Nonagrilab & Dummy variable for if HH is an industry worker. \\
Agrifar & Dummy variable for if HH is a farmer. \\
Agrifar-nw & Dummy variable for if HH living in the Northwest and agricultural farmer. \\
Sms & Dummy variable for if HH is self-employed or manager. \\
Another & Dummy variable for if HH has another type of job. \\
Nbbud & Number of participants in the household's budget. \\
Nactiff & Number of female workers. \\
Nactifm & Number of male workers. \\
Schooling level of HH & \\
Illiterate & Dummy variable for HH is illiterate. \\
Prim & Dummy variable for HH has a primary schooling level. \\
Sec-J & Dummy variable for HH has a junior secondary schooling level. \\
Sec-S & Dummy variable for HH has a senior secondary schooling level. \\
Higher & Dummy variable for HH has a higher educational level. \\
Nbetud & Number of students. \\
Nbelspv & Number of children in private secondary school. \\
Nbelspu & Number of children in public secondary school. \\
Nbelppv & Number of children in private primary school. \\
Nbelppu & Number of children in public primary school. \\
\hline
\end{tabular}

$\mathrm{HH}=$ 'household head'. Zone 1 corresponds to Greater Tunis, the most prosperous region and largest industrial center. Zone 5 corresponds to the Middle east (Sousse, Monastir, Mahdia), which is the second economic region of Tunisia. It is reputed for its thriving tourist industry. Since Zones 1 and 5 are omitted, the sign of the coefficients of the other zones should be negative in the prediction equation of living standards. Zone 2 is the Northest (Nabeul, Bizerte, Zaghouen), which is the third most important economic region of Tunisia. We expect the coefficient of this variable to have the smallest magnitude among the zone coefficients in the prediction equation. Zone 3 corresponds to the Northwest where the highest poverty incidence is. Its coefficient should have the largest magnitude among the zone coefficients. Zone 4 is the Middle west which is also very poor. Zone 6 is the Sfax area, which is economically prosperous as one the main industrial center after Tunis and the Middle east. Zone7 is the Southwest where Tozeur oasis stands as an important producing area of dates. It is also an increasingly prosperous tourism center. Other important towns in this area are Gafsa (with a declining production of phosphates) and Kbelli. Zone 8 is the Southeast, which includes Gabes (relatively wealthy although less than Sfax), Mednine and Tataouine. Its coefficient in the prediction equation should be negative.

As for the housing characteristics, the number of rooms per capita should be correlated with living standards. The omitted category for the housing type is 'villa'. Therefore, the coefficients of the remaining categories should have negative signs, especially for 'arab house' and 'hovel'.

The activities of members are likely to matter for living standards. The number of participants in the household budget (nbbud) and the number of male and female active members (respectively actifm, actiff) should be positively correlated with the living standard. The categories for professionals, managers, industrials and traders are omited in the prediction equations. Then, except for the category Agrifar (farmer), the included professional categories should have negative coefficients. The sign of the coefficient for farmer may be ambiguous because the questionnaire does not distinguish small and large producers. Moreover, no information on the cultivated areas or on the agricultural activity is available.

Education variables are often correlated with living standards. We omit the categories corresponding to university or the second cycle of the secondary level (at least 4 years of secondary education beyond the 6 years of primary education) for the education of the household head. The remaining categories are denoted: Illiterate (no education); Prim (6 years of primary education or less); Sec1 (3 years of secondary education or less). The coefficients of these dummy variables should be negative. Nbetud denotes the variable indicating the number of students in the household. Since education is likely to be a normal good, we expect its coefficient to be positively correlated with the household living standard. 
Table 2: Descriptive Statistics

\begin{tabular}{|c|c|c|c|c|}
\hline Variables & Mean & Std. Deviation & Minimum & Maximum \\
\hline Yearly total expenditure & 4066 & 3456 & 99 & 54234 \\
\hline Yearly total expend. p.c. & 804 & 809 & 47 & 20531 \\
\hline Great Tunis & 0.216 & 0.412 & 0 & 1 \\
\hline Northeast & 0.138 & 0.345 & 0 & 1 \\
\hline Northwest & 0.152 & 0.359 & 0 & 1 \\
\hline Middle East & 0.127 & 0.333 & 0 & 1 \\
\hline Middle west & 0.134 & 0.341 & 0 & 1 \\
\hline Sfax & 0.088 & 0.283 & 0 & 1 \\
\hline Southeast & 0.089 & 0.284 & 0 & 1 \\
\hline Southwest & 0.055 & 0.228 & 0 & 1 \\
\hline $\mathrm{Nc} 2$ & 0.322 & 0.565 & 0 & 4 \\
\hline Nc3-6 & 0.612 & 0.824 & 0 & 5 \\
\hline Nc7-11 & 0.748 & 0.933 & 0 & 5 \\
\hline Na12-18 & 0.995 & 1.167 & 0 & 7 \\
\hline $\mathrm{Na} 19 \mathrm{p}$ & 3.001 & 1.433 & 0 & 11 \\
\hline Age & 48.27 & 13.79 & 16 & 99 \\
\hline Nbroompc & 0.544 & 0.366 & 0.05 & 4.5 \\
\hline Detached House & 0.185 & 0.388 & 0 & 1 \\
\hline Flat & 0.048 & 0.214 & 0 & 1 \\
\hline Arab house & 0.733 & 0.442 & 0 & 1 \\
\hline Hovel & 0.033 & 0.179 & 0 & 1 \\
\hline Owner & 0.801 & 0.399 & 0 & 1 \\
\hline Rent & 0.079 & 0.269 & 0 & 1 \\
\hline Locvte & 0.061 & 0.239 & 0 & 1 \\
\hline Free & 0.059 & 0.235 & 0 & 1 \\
\hline Unemp & 0.014 & 0.117 & 0 & 1 \\
\hline Agrilab-se & 0.009 & 0.096 & 0 & 1 \\
\hline Agrilab-sw & 0.006 & 0.077 & 0 & 1 \\
\hline Agrilab-an & 0.076 & 0.265 & 0 & 1 \\
\hline Nonagrilab & 0.309 & 0.462 & 0 & 1 \\
\hline Agrifar & 0.137 & 0.344 & 0 & 1 \\
\hline Agrifar-nw & 0.031 & 0.173 & 0 & 1 \\
\hline Sms & 0.132 & 0.339 & 0 & 1 \\
\hline Another & & & & \\
\hline Nbbud & 0.518 & 1.116 & 0 & 8 \\
\hline Nactiff & 0.303 & 0.621 & 0 & 5 \\
\hline Nactim & 1.209 & 0.866 & 0 & 7 \\
\hline Illiterate & 0.476 & 0.499 & 0 & 1 \\
\hline Prim & 0.289 & 0.453 & 0 & 1 \\
\hline Sec-J & 0.072 & 0.258 & 0 & 1 \\
\hline Sec-S & 0.091 & 0.287 & 0 & 1 \\
\hline Higher & 0.041 & 0.197 & 0 & 1 \\
\hline Nbetud & 0.045 & 0.243 & 0 & 4 \\
\hline Nbelspv & 0.052 & 0.245 & 0 & 3 \\
\hline Nbelspu & 0.403 & 0.789 & 0 & 5 \\
\hline Nbelppv & 0.006 & 0.093 & 0 & 3 \\
\hline Nbelppu & 1.007 & 1.198 & 0 & 7 \\
\hline
\end{tabular}

7734 observations 
Table 3: Prediction Equations

The living standard variable is the equivalent income.

\begin{tabular}{|c|c|c|c|c|c|c|c|c|c|c|c|c|}
\hline Variables & OLS V1 & OLS V2 & OLS V3 & Tobit V1 & Tobit V2 & Tobit V3 & UQ01 V1 & UQ01 V2 & UQ01 V3 & CQ01 V1 & CQ01 V2 & CQ01 V3 \\
\hline Constant & $\begin{array}{c}6.631 \\
(0.000)\end{array}$ & $\begin{array}{c}6.38 \\
(0.000)\end{array}$ & $\begin{array}{c}6.567 \\
(0.000)\end{array}$ & $\begin{array}{c}6.574 \\
(0.000)\end{array}$ & $\begin{array}{c}6.135 \\
(0.000)\end{array}$ & $\begin{array}{c}6.363 \\
(0.000)\end{array}$ & $\begin{array}{c}5.779 \\
(0.000)\end{array}$ & $\begin{array}{c}5.832 \\
(0.000)\end{array}$ & $\begin{array}{c}6.000 \\
(0.000)\end{array}$ & $\begin{array}{c}5.779 \\
(0.000)\end{array}$ & $\begin{array}{c}5.992 \\
(0.000)\end{array}$ & $\begin{array}{c}6.04 \\
(0.000)\end{array}$ \\
\hline Northeast & $\begin{array}{l}-0.197 \\
(0.000)\end{array}$ & $\begin{array}{l}-0.061 \\
(0.004)\end{array}$ & $\begin{array}{c}-0.054 \\
(0.006)\end{array}$ & $\begin{array}{l}-0.245 \\
(0.000)\end{array}$ & $\begin{array}{l}-0.116 \\
(0.012)\end{array}$ & $\begin{array}{l}-0.102 \\
(0.025)\end{array}$ & $\begin{array}{l}-0.243 \\
(0.000)\end{array}$ & $\begin{array}{l}-0.069 \\
(0.040)\end{array}$ & $\begin{array}{l}-0.048 \\
(0.133)\end{array}$ & $\begin{array}{l}-0.243 \\
(0.000)\end{array}$ & $\begin{array}{c}-0.063 \\
(0.014)\end{array}$ & $\begin{array}{c}-0.037 \\
(0.149)\end{array}$ \\
\hline Northwest & $\begin{array}{l}-0.557 \\
(0.000)\end{array}$ & $\begin{array}{l}-0.364 \\
(0.000)\end{array}$ & $\begin{array}{c}-0.314 \\
(0.000)\end{array}$ & $\begin{array}{l}-0.545 \\
(0.000)\end{array}$ & $\begin{array}{l}-0.398 \\
(0.000)\end{array}$ & $\begin{array}{l}-0.340 \\
(0.000)\end{array}$ & $\begin{array}{l}-0.574 \\
(0.000)\end{array}$ & $\begin{array}{l}-0.398 \\
(0.000)\end{array}$ & $\begin{array}{l}-0.333 \\
(0.000)\end{array}$ & $\begin{array}{c}-0.574 \\
(0.000)\end{array}$ & $\begin{array}{c}-0.344 \\
(0.000)\end{array}$ & $\begin{array}{l}-0.288 \\
(0.000)\end{array}$ \\
\hline Mid. west & $\begin{array}{l}-0.496 \\
(0.000)\end{array}$ & $\begin{array}{l}-0.223 \\
(0.000)\end{array}$ & $\begin{array}{c}-0.19 \\
(0.000)\end{array}$ & $\begin{array}{l}-0.472 \\
(0.000)\end{array}$ & $\begin{array}{c}-0.272 \\
(0.000)\end{array}$ & $\begin{array}{l}-0.241 \\
(0.000)\end{array}$ & $\begin{array}{l}-0.534 \\
(0.000)\end{array}$ & $\begin{array}{c}-0.287 \\
(0.000)\end{array}$ & $\begin{array}{c}-0.261 \\
(0.000)\end{array}$ & $\begin{array}{c}-0.534 \\
(0.000)\end{array}$ & $\begin{array}{c}-0.294 \\
(0.000)\end{array}$ & $\begin{array}{l}-0.236 \\
(0.000)\end{array}$ \\
\hline Sfax & $\begin{array}{l}-0.336 \\
(0.000)\end{array}$ & $\begin{array}{l}-0.306 \\
(0.000)\end{array}$ & $\begin{array}{c}-0.274 \\
(0.000)\end{array}$ & $\begin{array}{l}-0.337 \\
(0.000)\end{array}$ & $\begin{array}{l}-0.356 \\
(0.000)\end{array}$ & $\begin{array}{l}-0.329 \\
(0.000)\end{array}$ & $\begin{array}{l}-0.390 \\
(0.000)\end{array}$ & $\begin{array}{l}-0.320 \\
(0.000)\end{array}$ & $\begin{array}{c}-0.288 \\
(0.000)\end{array}$ & $\begin{array}{l}-0.390 \\
(0.000)\end{array}$ & $\begin{array}{c}-0.240 \\
(0.000)\end{array}$ & $\begin{array}{l}-0.158 \\
(0.000)\end{array}$ \\
\hline Southeast & $\begin{array}{l}-0.350 \\
(0.000)\end{array}$ & $\begin{array}{l}-0.194 \\
(0.000)\end{array}$ & $\begin{array}{l}-0.151 \\
(0.000)\end{array}$ & $\begin{array}{l}-0.098 \\
(0.077)\end{array}$ & $\begin{array}{l}-0.003^{-} \\
(0.957)\end{array}$ & $\begin{array}{c}0.048^{-} \\
(0.411)\end{array}$ & $\begin{array}{l}-0.223 \\
(0.000)\end{array}$ & $\begin{array}{c}-0.041 \\
(0.256)\end{array}$ & $\begin{array}{l}-0.042 \\
(0.254)\end{array}$ & $\begin{array}{l}-0.223 \\
(0.000)\end{array}$ & $\begin{array}{c}0.005 \\
(0.851)\end{array}$ & $\begin{array}{c}0.041 \\
(0.159)\end{array}$ \\
\hline Southwest & $\begin{array}{c}-0.47 \\
(0.000)\end{array}$ & $\begin{array}{l}-0.273 \\
(0.000)\end{array}$ & $\begin{array}{c}-0.208 \\
(0.000)\end{array}$ & $\begin{array}{l}-0.381 \\
(0.000)\end{array}$ & $\begin{array}{l}-0.263 \\
(0.000)\end{array}$ & $\begin{array}{l}-0.176 \\
(0.000)\end{array}$ & $\begin{array}{l}-0.420 \\
(0.000)\end{array}$ & $\begin{array}{l}-0.239 \\
(0.000)\end{array}$ & $\begin{array}{l}-0.169 \\
(0.000)\end{array}$ & $\begin{array}{l}-0.420 \\
(0.000)\end{array}$ & $\begin{array}{l}-0.151 \\
(0.000)\end{array}$ & $\begin{array}{c}-0.088 \\
(0.005)\end{array}$ \\
\hline Age & & $\begin{array}{c}0.009 \\
(0.002)\end{array}$ & $\begin{array}{c}0.009 \\
(0.003)\end{array}$ & & $\begin{array}{c}0.007 \\
(0.259)\end{array}$ & $\begin{array}{c}0.009 \\
(0.116)\end{array}$ & & $\begin{array}{c}0.011 \\
(0.027)\end{array}$ & $\begin{array}{c}0.008 \\
(0.143)\end{array}$ & & $\begin{array}{c}0.006 \\
(0.099)\end{array}$ & $\begin{array}{c}0.003 \\
(0.479)\end{array}$ \\
\hline Age2 & & $\begin{array}{r}-0.0001 \\
(0.000)\end{array}$ & $\begin{array}{r}-0.0001 \\
(0.003)\end{array}$ & & $\begin{array}{r}-0.0001 \\
(0.079)\end{array}$ & $\begin{array}{r}-0.0001 \\
(0.084)\end{array}$ & & $\begin{array}{r}-0.0001 \\
(0.003)\end{array}$ & $\begin{array}{r}-0.0001 \\
(0.190)\end{array}$ & & $\begin{array}{r}-0.0001 \\
(0.024)\end{array}$ & $\begin{array}{c}-0.0000 \\
(0.573)\end{array}$ \\
\hline $\mathrm{Nc} 2$ & & $\begin{array}{l}-0.082 \\
(0.000)\end{array}$ & $\begin{array}{c}-0.084 \\
(0.000)\end{array}$ & & $\begin{array}{c}-0.068 \\
(0.001)\end{array}$ & $\begin{array}{c}-0.074 \\
(0.000)\end{array}$ & & $\begin{array}{l}-0.101 \\
(0.000)\end{array}$ & $\begin{array}{l}-0.077 \\
(0.000)\end{array}$ & & $\begin{array}{l}-0.113 \\
(0.000)\end{array}$ & $\begin{array}{l}-0.075 \\
(0.000)\end{array}$ \\
\hline Nc3-6 & & $\begin{array}{l}-0.115 \\
(0.000)\end{array}$ & $\begin{array}{l}-0.122 \\
(0.000)\end{array}$ & & $\begin{array}{l}-0.083 \\
(0.000)\end{array}$ & $\begin{array}{l}-0.098 \\
(0.000)\end{array}$ & & $\begin{array}{l}-0.104 \\
(0.000)\end{array}$ & $\begin{array}{l}-0.116 \\
(0.000)\end{array}$ & & $\begin{array}{c}-0.110 \\
(0.000)\end{array}$ & $\begin{array}{l}-0.120 \\
(0.000)\end{array}$ \\
\hline Nc7-11 & & $\begin{array}{l}-0.087 \\
(0.000)\end{array}$ & $\begin{array}{l}-0.122 \\
(0.000)\end{array}$ & & $\begin{array}{l}-0.062 \\
(0.000)\end{array}$ & $\begin{array}{l}-0.087 \\
(0.000)\end{array}$ & & $\begin{array}{l}-0.092 \\
(0.000)\end{array}$ & $\begin{array}{l}-0.108 \\
(0.000)\end{array}$ & & $\begin{array}{c}-0.100 \\
(0.000)\end{array}$ & $\begin{array}{l}-0.118 \\
(0.000)\end{array}$ \\
\hline $\mathrm{Na} 12-18$ & & $\begin{array}{l}-0.055 \\
(0.000)\end{array}$ & $\begin{array}{l}-0.116 \\
(0.000)\end{array}$ & & $\begin{array}{l}-0.033 \\
(0.003)\end{array}$ & $\begin{array}{l}-0.093 \\
(0.000)\end{array}$ & & $\begin{array}{c}-0.056 \\
(0.000)\end{array}$ & $\begin{array}{l}-0.114 \\
(0.000)\end{array}$ & & $\begin{array}{c}-0.052 \\
(0.000)\end{array}$ & $\begin{array}{l}-0.114 \\
(0.000)\end{array}$ \\
\hline $\mathrm{Na} 19 \mathrm{p}$ & & $\begin{array}{c}0.04 \\
(0.000)\end{array}$ & $\begin{array}{c}-0.050 \\
(0.000)\end{array}$ & & $\begin{array}{c}0.063 \\
(0.000)\end{array}$ & $\begin{array}{c}-0.024 \\
(0.039)\end{array}$ & & $\begin{array}{c}0.036 \\
(0.000)\end{array}$ & $\begin{array}{c}-0.05 \\
(0.000)\end{array}$ & & $\begin{array}{c}0.022 \\
(0.000)\end{array}$ & $\begin{array}{l}-0.057 \\
(0.000)\end{array}$ \\
\hline
\end{tabular}




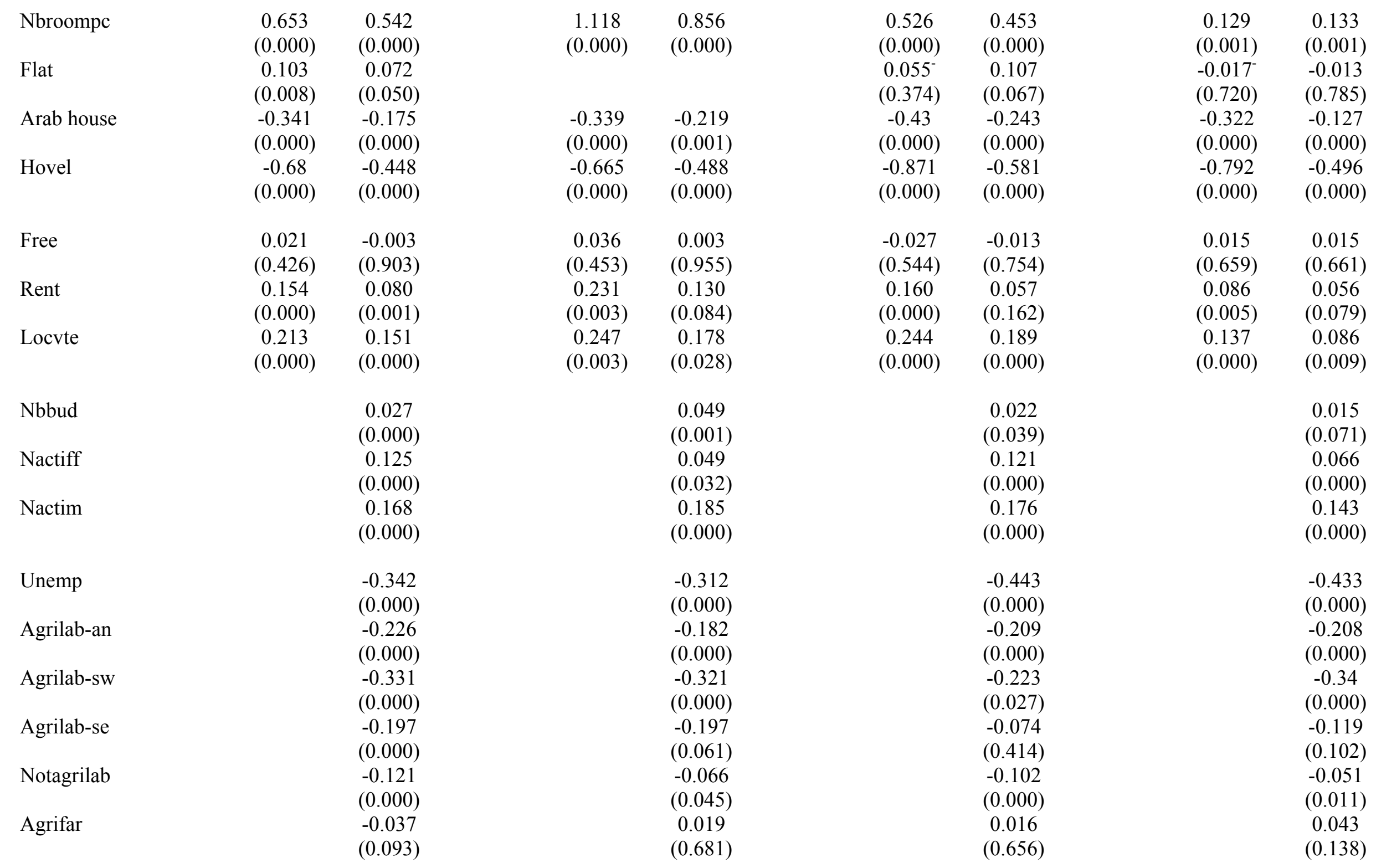




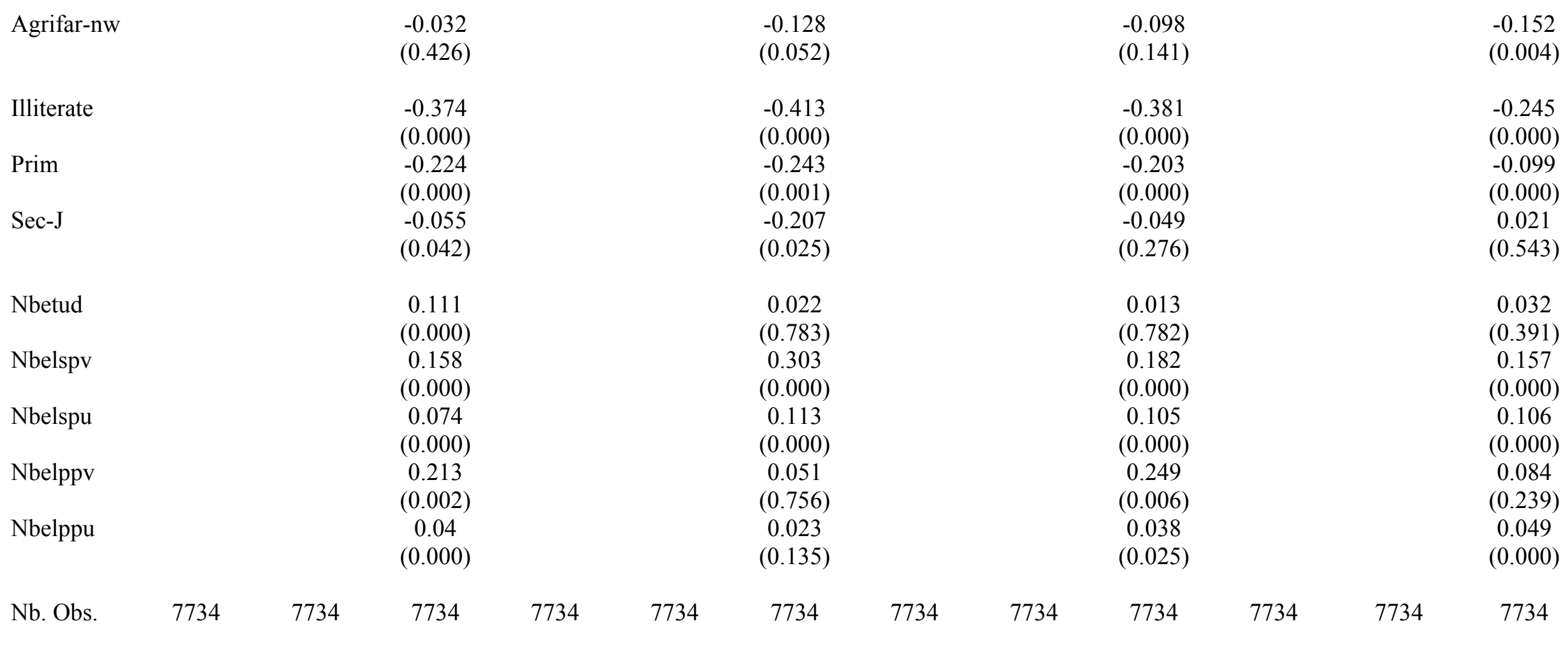

V1 : Version 1 estimation using Set I variables (regional variables).

V2 : Version 2 estimation using Set II variables (Set I + demographic and dwelling variables).

V3 : Version 3 estimation using Set III variables (Set II + occupation and schooling level of household head).

Tobit : Censored (10)

UQ01 : Uncensored quantile (0.1) regression.

CQ01 : Censored (50) quantile (0.1) regression.

$\mathrm{P}$-value in parentheses. 7734 observations 
Table 4: Variance of the Prediction Errors over the Variance of the Logarithms of Living Standards

Whole population

\begin{tabular}{|l|l|l|l|l|l|l|}
\hline & OLS & $\begin{array}{l}\text { Tobit } \\
\text { Threshold 10\% }\end{array}$ & $\begin{array}{l}\text { Tobit } \\
\text { Threshold 30\% }\end{array}$ & $\begin{array}{l}\text { Quantile } \\
\text { Regressions } \\
\text { (Quantile } \\
10 \%)\end{array}$ & $\begin{array}{l}\text { Quantile } \\
\text { Regressions } \\
\text { (Quantile } \\
30 \%)\end{array}$ & $\begin{array}{l}\text { Censored } \\
\text { Quantile } \\
\text { Regressions } \\
\text { Threshold } \\
50 \% \\
\text { (Quantile } \\
10 \%)\end{array}$ \\
\hline Set I & 0.897 & & & & & 3.251 \\
\hline Set II & 0.551 & 0.908 & 0.900 & 2.291 & 1.146 & 2.259 \\
\hline Set III & 0.473 & 0.635 & 0.568 & 1.413 & 0.693 & 1.991 \\
\hline
\end{tabular}

The poor under the first quintile

\begin{tabular}{|l|l|l|l|l|l|l|}
\hline & OLS & $\begin{array}{l}\text { Tobit } \\
\text { Threshold 10\% }\end{array}$ & $\begin{array}{l}\text { Tobit } \\
\text { Threshold 30\% }\end{array}$ & $\begin{array}{l}\text { Quantile } \\
\text { Regressions } \\
\text { (Quantile } \\
10 \%)\end{array}$ & $\begin{array}{l}\text { Quantile } \\
\text { Regressions } \\
\text { (Quantile } \\
30 \%)\end{array}$ & $\begin{array}{l}\text { Censored } \\
\text { Quantile } \\
\text { Regressions } \\
\text { Threshold } \\
50 \% \\
\text { Quantile } \\
10 \%)\end{array}$ \\
\hline Set I & 0.832 & & & & & \\
\hline Set II & 0.420 & 0.806 & 0.814 & 0.105 & 0.410 & 0.059 \\
\hline Set III & 0.338 & 0.408 & 0.406 & 0.080 & 0.210 & 0.062 \\
\hline
\end{tabular}

The poor under the second quintile

\begin{tabular}{|l|l|l|l|l|l|l|}
\hline & OLS & $\begin{array}{l}\text { Tobit } \\
\text { Threshold 10\% }\end{array}$ & $\begin{array}{l}\text { Tobit } \\
\text { Threshold 30\% }\end{array}$ & $\begin{array}{l}\text { Quantile } \\
\text { Regressions } \\
\text { (Quantile } \\
10 \%)\end{array}$ & $\begin{array}{l}\text { Quantile } \\
\text { Regressions } \\
\text { (Quantile } \\
30 \%)\end{array}$ & $\begin{array}{l}\text { Censored } \\
\text { Quantile } \\
\text { Regressions } \\
\text { Threshold } \\
50 \% \\
\text { (Quantile } \\
10 \%)\end{array}$ \\
\hline Set I & 0.845 & & & & & \\
\hline Set II & 0.428 & 0.448 & 0.423 & 0.147 & 0.211 & 0.158 \\
\hline Set III & 0.350 & 0.373 & 0.344 & 0.152 & 0.185 & 0.155 \\
\hline
\end{tabular}

7734 observations. 
Table 5: Measures of Targeting Efficiency for $z=T D 280$

The living standard variable is the equivalent income.

\begin{tabular}{|c|c|c|c|c|c|}
\hline & $\mathrm{P} 0$ & $\mathrm{P} 1$ & $\mathrm{P} 2$ & Leakage & Under-coverage \\
\hline SUBV & $\begin{array}{r}13.86 \\
(0.75)\end{array}$ & $\begin{array}{c}3.44 \\
(0.24)\end{array}$ & $\begin{array}{l}1.30 \\
(0.11)\end{array}$ & $\begin{array}{r}90.05 \\
(1.24)\end{array}$ & $\begin{array}{r}0.00 \\
(0)\end{array}$ \\
\hline OLS 1 & $\begin{array}{c}10.50 \\
(0.67)\end{array}$ & $\begin{array}{c}2.24 \\
(0.21)\end{array}$ & $\begin{array}{l}0.74 \\
(0.10)\end{array}$ & $\begin{array}{l}80.74 \\
(4.34)\end{array}$ & $\begin{array}{l}24.73 \\
(2.88)\end{array}$ \\
\hline OLS 2 & $\begin{array}{c}7.52 \\
(0.47)\end{array}$ & $\begin{array}{c}1.37 \\
(0.12)\end{array}$ & $\begin{array}{l}0.40 \\
(0.05)\end{array}$ & $\begin{array}{l}73.57 \\
(3.67)\end{array}$ & $\begin{array}{l}19.54 \\
(1.58)\end{array}$ \\
\hline OLS 3 & $\begin{array}{c}6.79 \\
(0.40)\end{array}$ & $\begin{array}{c}1.22 \\
(0.10)\end{array}$ & $\begin{array}{l}0.36 \\
(0.04)\end{array}$ & $\begin{array}{l}72.39 \\
(3.60)\end{array}$ & $\begin{array}{l}17.50 \\
(1.37)\end{array}$ \\
\hline TB10 1 & $\begin{array}{l}10.90 \\
(0.68)\end{array}$ & $\begin{array}{c}2.26 \\
(0.21)\end{array}$ & $\begin{array}{l}0.74 \\
(0.09)\end{array}$ & $\begin{array}{l}80.88 \\
(4.43)\end{array}$ & $\begin{array}{l}33.26 \\
(3.24)\end{array}$ \\
\hline TB10 2 & $\begin{array}{c}7.58 \\
(0.47)\end{array}$ & $\begin{array}{c}1.34 \\
(0.11)\end{array}$ & $\begin{array}{c}0.38 \\
(0.04)\end{array}$ & $\begin{array}{l}73.26 \\
(3.98)\end{array}$ & $\begin{array}{l}20.89 \\
(1.67)\end{array}$ \\
\hline TB10 3 & $\begin{array}{c}6.76 \\
(0.42)\end{array}$ & $\begin{array}{l}1.15 \\
(0.09)\end{array}$ & $\begin{array}{c}0.32 \\
(0.03)\end{array}$ & $\begin{array}{l}71.82 \\
(3.88)\end{array}$ & $\begin{array}{l}19.50 \\
(1.51)\end{array}$ \\
\hline TB30 1 & $\begin{array}{l}10.71 \\
(0.67)\end{array}$ & $\begin{array}{c}2.25 \\
(0.21)\end{array}$ & $\begin{array}{c}0.74 \\
(0.10)\end{array}$ & $\begin{array}{l}80.84 \\
(4.51)\end{array}$ & $\begin{array}{l}33.26 \\
(3.24)\end{array}$ \\
\hline TB30 2 & $\begin{array}{c}7.29 \\
(0.46)\end{array}$ & $\begin{array}{c}1.32 \\
(0.11)\end{array}$ & $\begin{array}{l}0.38 \\
(0.04)\end{array}$ & $\begin{array}{l}73.17 \\
(3.69)\end{array}$ & $\begin{array}{c}19.40 \\
(1.55)\end{array}$ \\
\hline TB30 3 & $\begin{array}{c}6.63 \\
(0.40)\end{array}$ & $\begin{array}{c}1.16 \\
(0.09)\end{array}$ & $\begin{array}{c}0.33 \\
(0.03)\end{array}$ & $\begin{array}{l}71.86 \\
(3.63)\end{array}$ & $\begin{array}{c}16.50 \\
(1.34)\end{array}$ \\
\hline QR10 1 & $\begin{array}{c}10.91 \\
(0.66)\end{array}$ & $\begin{array}{c}2.19 \\
(0.19)\end{array}$ & $\begin{array}{l}0.68 \\
(0.08)\end{array}$ & $\begin{array}{r}80.37 \\
(3.41)\end{array}$ & $\begin{array}{c}13.15 \\
(1.97)\end{array}$ \\
\hline QR10 2 & $\begin{array}{c}8.16 \\
(0.53)\end{array}$ & $\begin{array}{c}1.24 \\
(0.11)\end{array}$ & $\begin{array}{l}0.31 \\
(0.04)\end{array}$ & $\begin{array}{l}72.75 \\
(3.11)\end{array}$ & $\begin{array}{l}9.04 \\
(1.00)\end{array}$ \\
\hline QR10 3 & $\begin{array}{c}6.89 \\
(0.45)\end{array}$ & $\begin{array}{c}1.01 \\
(0.09)\end{array}$ & $\begin{array}{l}0.25 \\
(0.03)\end{array}$ & $\begin{array}{l}70.85 \\
(3.07)\end{array}$ & $\begin{array}{l}8.09 \\
(0.91)\end{array}$ \\
\hline QR30 1 & $\begin{array}{l}10.58 \\
(0.66)\end{array}$ & $\begin{array}{c}2.21 \\
(0.20)\end{array}$ & $\begin{array}{l}0.72 \\
(0.09)\end{array}$ & $\begin{array}{l}80.52 \\
(3.88)\end{array}$ & $\begin{array}{l}24.73 \\
(2.88)\end{array}$ \\
\hline QR30 2 & $\begin{array}{c}7.51 \\
(0.49)\end{array}$ & $\begin{array}{c}1.24 \\
(0.11)\end{array}$ & $\begin{array}{l}0.33 \\
(0.04)\end{array}$ & $\begin{array}{l}72.61 \\
(3.31)\end{array}$ & $\begin{array}{l}13.71 \\
(1.32)\end{array}$ \\
\hline QR30 3 & $\begin{array}{c}6.52 \\
(0.40)\end{array}$ & $\begin{array}{c}1.07 \\
(0.09)\end{array}$ & $\begin{array}{l}0.30 \\
(0.03)\end{array}$ & $\begin{array}{l}71.27 \\
(3.35)\end{array}$ & $\begin{array}{l}12.93 \\
(1.16)\end{array}$ \\
\hline QRC01 1 & $\begin{array}{c}10.91 \\
(0.66)\end{array}$ & $\begin{array}{r}2.19 \\
(0.19)\end{array}$ & $\begin{array}{l}0.68 \\
(0.08)\end{array}$ & $\begin{array}{r}80.37 \\
(3.42)\end{array}$ & $\begin{array}{l}13.15 \\
(1.97)\end{array}$ \\
\hline QRC01 2 & $\begin{array}{c}8.45 \\
(0.55)\end{array}$ & $\begin{array}{c}1.36 \\
(0.11)\end{array}$ & $\begin{array}{l}0.35 \\
(0.04)\end{array}$ & $\begin{array}{l}73.77 \\
(3.02)\end{array}$ & $\begin{array}{c}8.19 \\
(0.95)\end{array}$ \\
\hline QRC01 3 & $\begin{array}{c}7.37 \\
(0.48)\end{array}$ & $\begin{array}{c}1.09 \\
(0.09)\end{array}$ & $\begin{array}{l}0.27 \\
(0.03)\end{array}$ & $\begin{array}{l}71.54 \\
(3.09)\end{array}$ & $\begin{array}{c}6.01 \\
(0.76)\end{array}$ \\
\hline
\end{tabular}

Set I of independent variables includes only regional variables. Set II includes in addition to Set I, demographic and dwelling variables. Set III includes in addition to Set II, occupation and schooling level of household head. SUBV: Current subsidies scheme.

OLS 1: Transfers based on OLS 1 : Set I variables.

OLS 2: Transfers based on OLS 2 : Set II variables.

OLS 3: Transfers based on OLS 3 : Set III variables.

TB10 1: Transfers based on Tobit censured at 10 percent with Set I variables.

TB10 2: Transfers based on Tobit censured at 10 percent with Set II variables.

TB10 3: Transfers based on Tobit censured at 10 percent with Set III variables.

TB30 1: Transfers based on Tobit censured at 30 percent with Set I variables. 
TB30 2: Transfers based on Tobit censured at 30 percent with Set II variables.

TB30 3: Transfers based on Tobit censured at 30 percent with Set 3 variables.

QR10 1: Transfers based on quantile regressions centered on quantile 0.1 with Set I variables.

QR10 2: Transfers based on quantile regressions centered on quantile 0.1 with Set II variables.

QR10 3: Transfers based on quantile regressions centered on quantile 0.1 with Set III variables.

QR30 1: Transfers based on quantile regressions centered on quantile 0.3 with Set 1 variables.

QR30 2: Transfers based on quantile regressions centered on quantile 0.3 with Set II variables.

QR30 3: Transfers based on quantile regressions centered on quantile 0.3 with Set I variables.

QRC01 1: Transfers based on censored quantile regressions centered on quantile 0.3 , censored at quantile 0.5 , with Set I variables.

QRC01 2: Transfers based on censored quantile regressions centered on quantile 0.3 , censored at quantile 0.5 , with Set II variables.

QRC01 3: Transfers based on censored quantile regressions centered on quantile 0.3 , censored at quantile 0.5 , with Set III variables.

Each of measures presented in this table has been multiplied by 100 for easy interpretation.

7734 observations. 


\section{Appendix 2: The estimation of the equivalent-incomes}

The calculus of the equivalent-incomes is based on the estimation of a food demand system. Non-food products have been excluded from the estimation because no price data are available for these products. We consider that the spatial variation of prices is such that households living within a cluster face the same price vector, a usual convention (Deaton, 1988). Further, we assume that before the implementation of the food subsidy scheme, household $h$ living in cluster $c$ has an exogenous income $y_{c}^{h}$ and faces the price vector $\mathbf{p}_{c}^{o}$. After the food subsidies, household $h$ faces a new price vector $\mathbf{p}_{c}^{p}$. To compare the living standards of households facing different prices, we choose a reference price vector, denoted by $\mathbf{p}^{r}$, and we define the equivalent-income as in King (1983). For a given budget constraint (p,y), the household equivalent income is defined as the income level which allows the same utility level at the reference prices. Formally, we have $v\left(\mathbf{p}^{r}, y_{e}\right)=v(\mathbf{p}, y)$, where $v($.$) is the indirect utility function, \mathbf{p}$ is a price vector, and $y$ is a vector of the household per capita living standards. We use income per capita for the living standard indicator to avoid complications in the definition of equivalent scales. Because $\mathbf{p}^{r}$ is fixed across all households, and $y_{e}$ is an increasing monotonic transformation of $v($.$) , variable y_{e}$ is an exact monetary metric of the actual utility $v(\mathbf{p}, y)$. The equivalent-income function $y_{\mathrm{e}}($.$) can also be obtained in terms of the expenditure function e($.$) :$ $y_{e}=e\left(\mathbf{p}^{r} ; v(\mathbf{p}, y)\right)=y_{e}\left(\mathbf{p}^{r}, \mathbf{p}, y\right)=\Gamma$ as a short-script notation.

A measure of the households' valuation of the food subsidy programme is the change in their equivalent-income consecutive to the subsidies. This measure is denoted the equivalent-gain per capita of the subsidy programme for household $h, \mathrm{E}_{\mathrm{FS}}^{h}$, and it is given by $\mathrm{E}_{F S}^{h}=y_{e}\left(\mathbf{p}^{r}, \mathbf{p}_{c}^{F S}, y^{h}\right)-y_{e}\left(\mathbf{p}^{r}, \mathbf{p}_{c}^{r}, y^{h}\right)$, where 'FS' indicates that the considered programme is that of food subsidies.

Now, if direct transfers $T_{c}{ }_{c}$ are awarded to households predicted poor after removing food subsidy programme, the valuation of moving from the reference situation to the new situation for household $h$ is $\mathrm{E}_{c}^{h}(\hat{T})=y_{e}\left(\mathbf{p}^{r}, \mathbf{p}_{c}^{r}, y_{c}^{h}+\hat{T}_{c}^{h}\right)-y_{e}\left(\mathbf{p}^{r}, \mathbf{p}_{c}^{r}, y_{c}^{h}\right)$. Then, poverty measured by $\mathrm{P}_{\alpha}$ will fall following targeting by indicators instead of subsidies if $\mathrm{P}_{\alpha}\left[z_{e}, y_{e}\left(\mathbf{p}^{r}, \mathbf{p}_{c}^{r}, y+\hat{T}\right)\right]-\mathbf{P}_{\alpha}\left[z_{e}, y_{e}\left(\mathbf{p}^{r}, \mathbf{p}_{c}^{F S}, y\right)\right]<0$, and $z_{e}$ is the equivalent-income function applied to the poverty line.

The equivalent income $y_{e}$ for each household is calculated from the estimates of the QAIDS of Banks et al. (1993). The wage share of commodity $\mathrm{j}$ in this system is

$$
\begin{array}{ll}
w_{j}(\mathbf{p}, y)=\omega_{j}^{*}+\sum_{k}^{K} \theta_{j k} \ln \left(p_{c k}\right)+\gamma_{j} \ln \left(\frac{y}{z\left(\mathbf{p}_{c}\right)}\right)+\frac{\delta_{j}}{\delta\left(\mathbf{p}_{c}\right)}\left[\ln \left(\frac{y}{z\left(\mathbf{p}_{c}\right)}\right)\right]^{2}, \\
\ln z\left(\mathbf{p}_{c}\right)=\ln \left(\omega_{0}\right)+\sum_{j} \omega_{j} \ln \left(p_{c j}\right)+\frac{1}{2} \sum_{j} \sum_{k} \theta_{j k}^{*} \ln \left(p_{c j}\right) \ln \left(p_{c k}\right), \delta\left(\mathbf{p}_{c}\right)=\prod_{k} p_{c k}^{\delta_{k}} \text { with } \sum_{k} \delta_{k}=0,
\end{array}
$$

$p_{c j}$ is the price of good $j$ in cluster $c, p_{c}$ is the price vector for cluster $j, y$ is the income and where $\omega_{0}, \omega_{\mathrm{j}}, \omega_{\mathrm{j}}^{*}, \theta_{\mathrm{jk}}, \theta_{\mathrm{jk}}^{*}, \delta_{\mathrm{j}}$ and $\gamma_{\mathrm{j}}$ are parameters to estimate.

Once the parameters of the QAIDS model are estimated, it is possible to compute the equivalent-income of each household, for any price vector $p_{c}^{s}$ and any transfer $T^{h}$. This yields

$$
\ln y_{e}\left(\mathbf{p}^{r}, \mathbf{p}_{c}^{s}, y_{c}^{h}+T_{c}^{h}\right)=\left[b\left(\mathbf{p}^{r}\right)-\ln z\left(\mathbf{p}^{r}\right)\right]\left[\left(\frac{\ln \left(y_{c}^{h}+T_{c}^{h}\right)-\ln z\left(\mathbf{p}_{c}^{s}\right)}{b\left(\mathbf{p}_{c}^{s}\right)-\ln z\left(\mathbf{p}_{c}^{s}\right)}\right)^{-1}+\delta\left(\mathbf{p}^{r}\right)-\delta\left(\mathbf{p}_{c}^{s}\right)\right]^{-1}+\ln z\left(\mathbf{p}^{r}\right),
$$

$\ln b\left(\mathbf{p}_{c}\right)=\ln z\left(\mathbf{p}_{c}\right)+\prod_{j} p_{c j}^{\gamma_{j}}$. The demand system estimates are presented in Muller and Bibi (2005). 


\section{REFERENCES}

Africa Focus Bulletin, 2006, “Africa: Social Transfers,” African Studies Center, University of Pennsylvania, February.

Ahmed, A.U. and H.E. Bouis, 2002, "Weighing what's practical: proxy means tests for targeting food subsidies in Egypt," Food Policy, 27, 519-540.

Alderman, H. and K. Lindert, 1998, "The potential and limitations of self-targeting food subsidies," The World Bank Research Observer, vol. 13, Issue 2, 213-230.

Atkinson, A. B., 1995, "On Targeting Social Security: Theory and Western Experience with Family Benefits." in Dominique van de Walle and Kimberly Nead (eds.), Public Spending and the Poor, Theory and Evidence. Pp. 25-68. The Johns Hopkins University Press for the World Bank.

Ayadi, M. and M. S. Matoussi, 1999, "Analyse de la Pauvreté en Tunisie: Comparaison Spatiale et Temporelle en Utilisant des Enquêtes Ménages, " Paper presented in the ERF Sixth Annual Conference, Cairo, 28-31 October.

Baker, J. and M. E. Grosh, 1994, "Poverty Reduction Through Geographic Targeting: How Well Does It Work, " World Development, vol. 22: 983-995.

Banks, J., R. Blundell and A. Lewbel, 1997, "Quadratic Engel Curves, Welfare Measurement and Consumer Demand," The Review of Economics and Statistics, Vol. LXXIX, No. 4, November.

Bardhan, P. and D. Mookherjee, 2006, "Pro-poor targeting and accountability of local governments in West Bengal," Journal of Development Economics, 79, 303-327.

Besley, T., 1990, "Means Testing Versus Universal Provision in Poverty Alleviation," Economica, vol. 57: 119129.

Besley, T. and S. Coate, 1992, "Workfare vs. Welfare: Incentive Arguments for Work Requirements in Poverty Alleviation Programs, " American Economic Review, vol. 82: 249-261.

Besley, T. and R. Kanbur, 1988, "Food Subsidies and Poverty alleviation, " The Economic Journal, vol. 98: 701719.

Besley, T. and R. Kanbur, 1993, "Principles of Targeting," in Michael Lipton and Jacques van der Gaag (eds.), Including the Poor, Pp. 67-90, The World Bank, Washington, D.C.

Bibi, S., 2003, "Comparing the Impact of Food Subsidies and Regional Targeting on Poverty: Evidence from Tunisia. " Journal of Development and Economic Policies, vol. 6 (1): 5-37.

Bibi, S. and J.-Y. Duclos, 2006, "Equity and policy effectiveness with imperfect targeting," Forthcoming Journal of Development Economics.

Bigman and Fofack, 2000, "Geographical Targeting for Poverty Alleviation: An Introduction to the Special Issue,” The World Bank Economic Review, vol. 14: 129-145.

Bigman, D. and P.V. Srinivasan, 2002, "Geographical Targeting of Poverty Alleviation Programs: Methodology and Application in Rural India,” Journal of Policy Modelling, 24, 237-255.

Blundell, R. and A. Lewbel, 1991, “The Information Content of Equivalence Scales," Journal of Econometrics, vol. 50: 49-68.

Bourguignon, F. and G. Fields, 1990, “Poverty Measures and Anti-Poverty Policy,” Recherches Economiques de Louvain, 56 (3-4). 
Bourguignon, F. and G. Fields, 1997, "Discontinuous Losses from Poverty, General $\mathrm{P}_{\alpha}$ Measures, and Optimal Transfers to the Poor," Journal of Public Economic, vol. 63: 155-175.

Buchinsky, M., 1994, "Changes in the U.S. Wage Structure 1963-1987: Application of Quantile Regression," Econometrica, Vol. 62, No. 2, 405-458, March.

Buchinsky, M. and J. Hahn, 1998, “An Alternative Estimator for the Censored Quantile Regression Model," Econometrica, Vol. 66, No. 3, 653-671, May.

Case, A. and A. Deaton, 1998 "Large Cash Transfers to the Elderly in South Africa," The Economic Journal, Vol. 108, No. 450, 1330-1361.

Chakravaty, S. R. et D. Mukherjee, 1998, “Optimal Subsidy for the Poor,” Economics Letters, vol. 61: 313-319. North-Holland.

Coady, D.P., M. Grosh and J. Hoddinott, 2002, “Targeting anti-poverty interventions: A selected annotated bibliography," mimeo The World Bank.

Coady, D.P., M. Grosh and J. Hoddinott, 2004, “Targeting Outcomes Redux," World Bank Research Observer, vol. 19, No. 1, 61-85, Spring.

Cornia, G. A. and F. Stewart, 1995, "Two Errors of Targeting," in Dominique van de Walle and Kimberly Nead (eds.), Public Spending and the Poor, Theory and Evidence. Pp. 350-386. The Johns Hopkins University Press for the World Bank.

Cowell, F.A. and M.-P., 1996, Victoria-Feser, "Poverty Measurement with Contaminated Data: A Robust Approach,” European Economic Review, 40, 1761-1771.

Creedy, J., 1996, "Comparing Tax and Transfer System: Poverty, Inequality and Target Efficiency," Economica, vol. 63, pp. 163-174.

Datt, G. and M. Ravallion, 1993, "Regional Disparities, Targeting and Poverty in India," in Michael Lipton and Jaques Van Der Gaag (eds.), Including the Poor. Pp. 91-114. The World Bank, Washington, D. C.

Datt, G. and M. Ravallion, 1994, "Transfer Benefits from Public Works Employment: Evidence for Rural India," Economic Journal, vol. 104: 1346-1369.

Deaton, A., 1981, “Optimal Taxes and the Structure of Preferences,” Econometrica, Vol. 49, No. 5, September.

Deaton, A., 1988, "Quality, Quantity and Spatial Variation of Prices," The American Economic Review, vol. 78 (3), pp. 418-430.

Deaton, A., 1997, "The Analysis of Household Survey: A Microeconomic Approach to Development Policy," John Hopkins University Press.

De Janvry, A., F. Finan, E. Sadoulet and R. Vakis, 2006, “Can conditional cash transfer programs serve as safety nets in keeping children at school and from working when exposed to shocks?", Journal of Development Economics, 79, 349-373.

De Janvry and E. Sadoulet, 2006a, "When to use a CCT versus a CT approach," mimeo University of California at Berkeley, July.

De Janvry and E. Sadoulet, 2006b, "Making Conditional Cash Transfer Programs More Efficient: Designing for Maximum Effect of the Conditionality," The World Bank Economic Review, Vol. 20, No. 1, 1-29.

DFID, 2006, "Using social transfers to improve human development," Social protection briefing note series, No. 3 , February. 
Elbers, C., J.O. Lanjouw and P. Lanjouw, 2003, "Micro-Level Estimation of Poverty and Inequality," Econometrica, Vol. 71, No. 1, 355-364, January.

Foster, J., J. Greer, and E. Thorbecke, 1984, “A Class of Decomposable Poverty Measures,” Econometrica, vol. 52: 761-765.

Galasso, E. and M. Ravallion, 2005, "Decentralized targeting of an antipoverty program," Journal of Public Economics, 89, 705-727.

Gassmann, F. and G. Notten, 2006, "Size matters: Poverty reduction effects of means-tested and universal child benefits in Russia," mimeo Maastricht Graduate School of Governance, January.

Glewwe, P., 1992, "Targeting Assistance to the Poor, Efficient Allocation of Transfers when Household Income is not Observed," Journal of Development Economics, vol. 38: 297-321.

Glewwe, P. et O. Kanan, 1989, "Targeting Assistance to the Poor: A Multivariate Approach Using Household Survey Data," Policy Planning and Research Working Paper, \# 86, Washington, D.C.

Grosh, M. and J.L. Baker, 1995, “Proxy Means Tests for Targeting Social Programs,” LSMS Working Paper, N. 118, The World Bank, Washington, D.C.

Gutner, T., "The political economy of food subsidy reform: the case of Egypt," Food Policy, 27, 455-476.

Hahn, J., 1995, “Bootstrapping Quantile Regression Estimators,” Econometric Theory, vol. 11, 105-121.

Hanmer, L.C., L. Bijlmakers, M.T. Basset, D. Sanders and G. Chapman, 1998, "Human Capital, Targeting and Social Safety Nets: An Analysis of Household Data from Zimbabwe," Oxford Development Studies, vol. 26, No. 2 .

Hassan, F.M.A., "Tunisia: Understanding Successful Socioeconomic Development," The World Bank, Washington, 2006.

Kanbur, R., 1987, "Measurement and Alleviation of Poverty, With an Application to the Effects of Macroeconomic Adjustment," IMF Staff Papers, vol. 34: 60-85.

King, M. A., 1983, "Welfare Analysis of Tax Reforms using Household Data," Journal of Public Economics, vol. 21: 183-214.

Koenker, R. and G. Bassett, 1978, "Regression Quantiles,” Econometrica, 46, 33-50.

Lindert, K., E. Skoufias and J. Shapiro, 2005, "Redistributing Income to the Poor and the Rich: Public Transfers in Latin America and the Caribbean," Discussion Draft, LACEA, October.

Muller, C., 2002, "Prices and Living Standards. Evidence for Rwanda," Journal of Development Economics, Vol. 68, 187-203.

Muller, C., 2002, "Censored Quantile Regressions of Chronic and Transient Poverty in Rwanda," Journal of African Economies, Vol.1, No. 4, pp. 503-541, 2002.

Muller, C, “Poverty Incidence and Poverty Change in Tunisia 1990-95”, mimeo University of Alicante, 2004.

Muller, C. and S. Bibi, 2006, “A Quadratic Almost Ideal Demand System for Tunisia”, mimeo Universidad de Alicante.

Park, A., S. Wang, and G. Wu., 2002, "Regional Poverty Targeting in China," Journal of Public Economics, vol. 86, pp. 123-153.

Pollak, R. A. et T. J. Wales, 1979, "Welfare Comparison and Equivalence Scales," The American Economic Review, vol. 69: 216-221. 
Powell, J. L., “Censored Regression Quantiles,” Journal of Econometrics, vol 32, 1986.

Pudney, S., "On Some Statistical Methods for Modelling the Incidence of Poverty," Oxford Bulletin of Economics and Statistics, 61, 3, 385-408, 1999.

Ravallion, M., 1989, “Land-Contingent Rural Poverty Alleviation Schemes," World Development, vol. 17: 12231233.

Ravallion, M., 1991, "On coverage of public employment schemes for poverty alleviation," Journal of Development Economics, 34, 57-79.

Ravallion, M., 1992, "Poverty Alleviation Through Regional Targeting: A case Study for Indonesia," in Avishay Braverman, Karla Hoff, and Joseph Stiglitz (eds.), The Economics of Rural Organization. Oxford University Press for the World Bank.

Ravallion, M., 2005, “Targeted transfers in poor countries: revisiting the tradeoffs and policy,” WPS3048, World Bank Development Research Group, May.

Ravallion, M. and K. Chao, 1989, "Targeted Policies for Poverty Alleviation under Imperfect Information: Algorithms and Applications," Journal of Policy Modeling, vol. 11: 213-224.

Ravallion, M. and G. Datt, 1995, "Is Targeting Through a Work Requirement Efficient? Some Evidence for Rural India," in Dominique van de Walle and Kimberly Nead (eds.), Public Spending and the Poor, Theory and Evidence. Pp. 413-444.

Ravallion, M. and D. Van de Walle, “A Profile of Poverty in Tunisia 1990”, Document Policy Research Department, World Bank, 1993.

République Tunisienne, 1991, "Séminaire National sur les Politiques de Promotion Sociale des Catégories de Population les plus Défavorisés,” Ministère des Affaires Sociales, Juin.

Schady, N. R., 2002, "Picking the Poor: Indicators for Geographic Targeting in Peru," Review of Income and Wealth, Serie 48, No. 3, September.

Slesnick, D.T. , 1996, "Consumption and Poverty: How Effective are In-Kind Transfers," The Economic Journal, November, 106, 1527-1545.

Tabor, S. R., 2002a, "Assisting the Poor with Cash: Design and Implementation of Social Transfer Programs," Social Protection Discussion Paper Series No. 0223, The World Bank, Washington D.C.

Tabor, S. R., 2002b, “Direct Cash Transfers,” Social Safety Net Primer Serie, June.

The World Bank, 1995, "Republic of Tunisia, Poverty Alleviation: Preserving Progress while Preparing for the Future," Middle East and North Africa Region, Report N 13993-TUN, Washington D.C.

The World Bank, 2000, “A Profile of Poverty in Tunisia 1995,” Washington D.C.

The World Bank, 2004, "Republic of Tunisia. Country Assistance Strategy for the period of July 2004 to July 2008," Public Information Notice 105, The World Bank, Washington D.C.

Van de Walle, D., 1998, “Assessing the Welfare Impacts of Public Spending,” World Development, Vol. 26, No. 3, 365-379. 

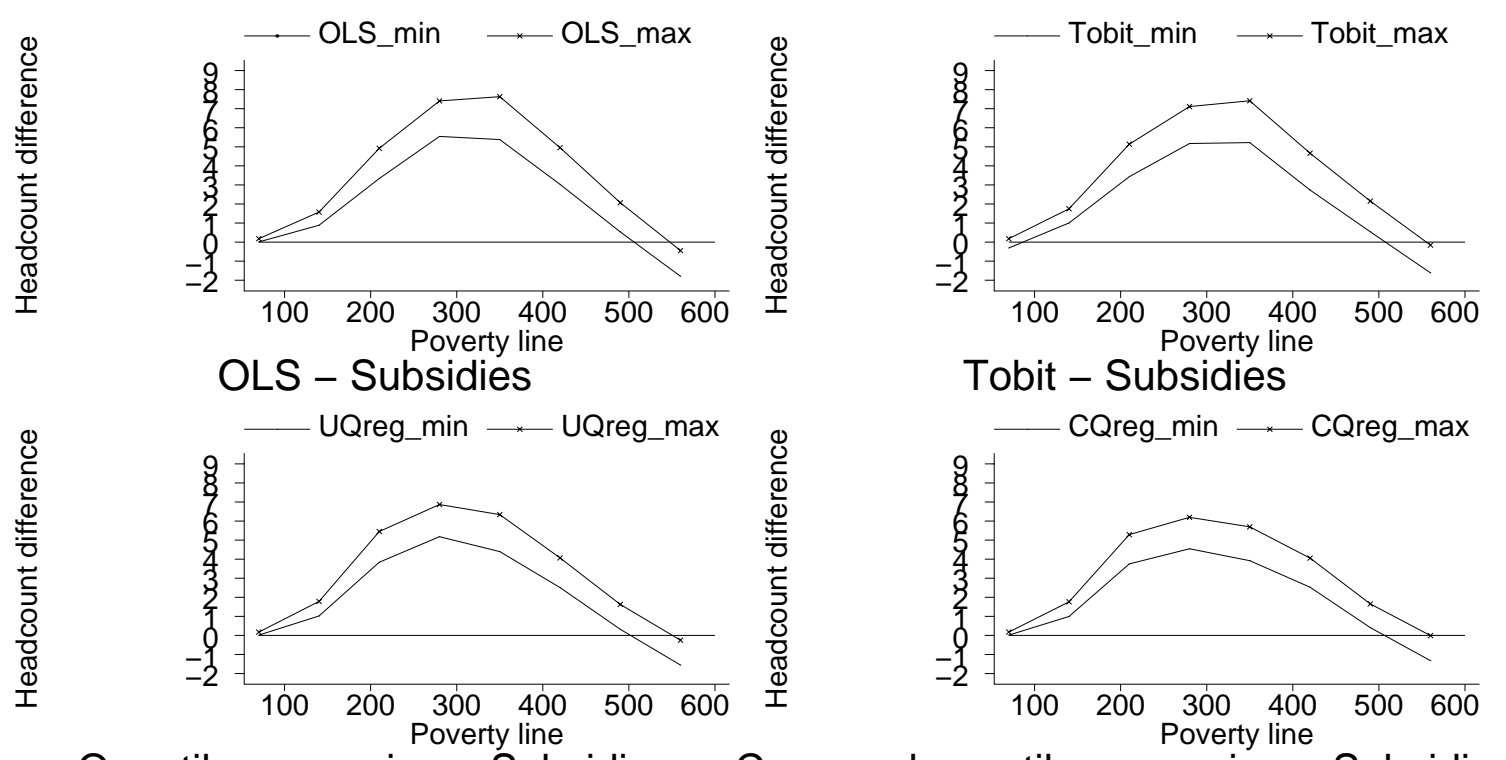

Quantile regression - Subsidies Censored quantile regression - Subsidies

\section{Confidence Intervals \\ Figure 1: Differences of Poverty Curves}

SIवाव 

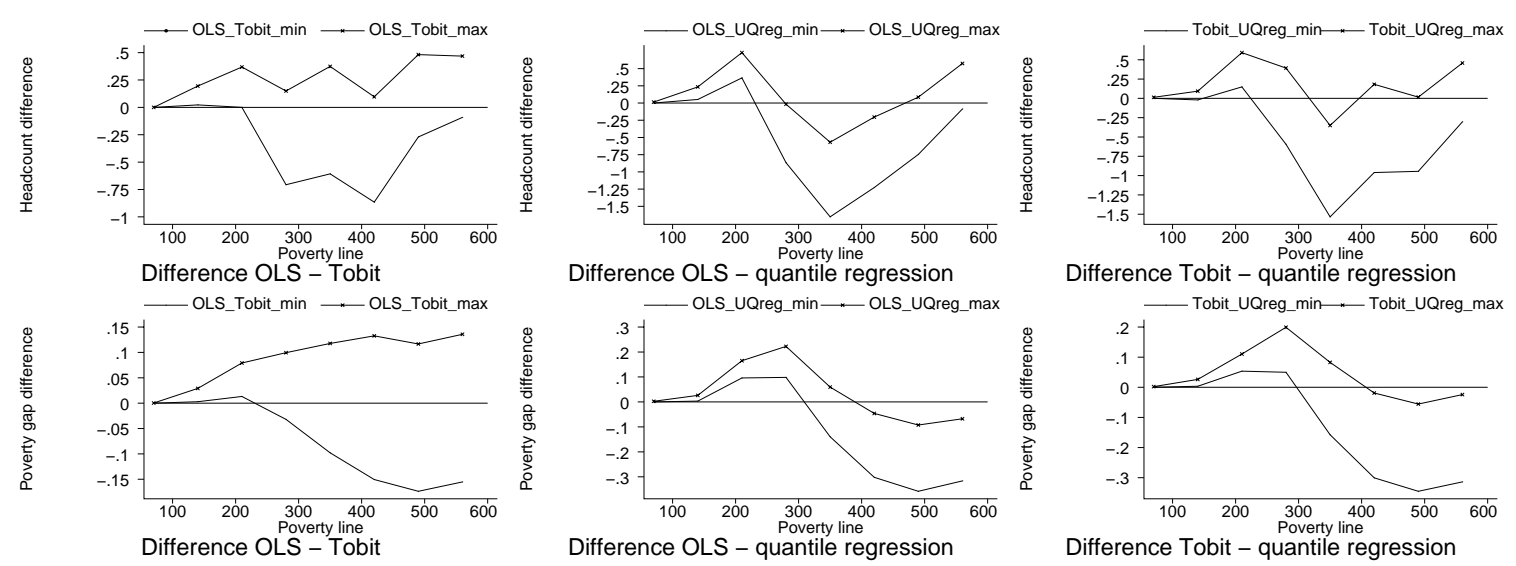

Difference Tobit - quantile regression

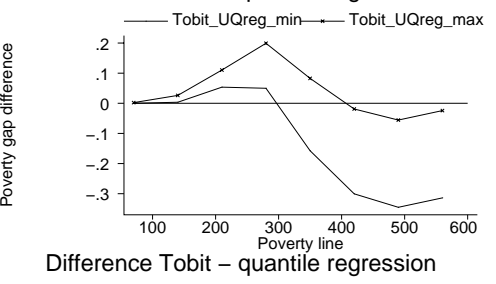

\section{Confidence Intervals}

Figure 2: Differences of Poverty Curves

जावाव 